\title{
Dynamics of Indigenous Socialization Strategies and Emotion Regulation Adjustment among Nso Early Adolescents, North West Region of Cameroon
}

\author{
Therese Mungah Shalo Tchombe Ph.D. \\ Emeritus Professor of Applied Cognitive Developmental Psychology, UNESCO Chair for Special \\ Needs Education, University of Buea, Cameroon P.O. Box 63 \\ Director, Centre for Research in Child and Family Development \& Education (CRCFDE) \\ P.O. Box 901, Limbe, Cameroon \\ Tani Emmanuel Lukong, Ph.D. \\ Lecturer, University of Buea, Founder, "Foundation of ScientificResearch, Community Based \\ Rehabilitation and Advocacy on Inclusive Education" (FORCAIE-CAMEROON) \\ lukongemms_20@yahoo.com
}

\begin{abstract}
Cultural values vary across cultures and social ecologies. Cultural communities define and endorse human abilities they perceive to give expression to their core values. This study aimed to examine the interaction among specific indigenous strategies of socialization such as indigenous proverbs, and indigenous games) within an eco-cultural setting which dictate a more cultural specific dimension on emotion regulation adjustment with keen attention on social competence skills and problem solving skills through an indigenized conceptual model of the Nso people of Cameroon. The study had three objectives; the study had a sample of 272. Results indicate that, proverbs and indigenous games influence early adolescence emotion regulation adjustment. This relationship is both directly and indirectly related to parents' emotion socialization behaviours and children's social and emotion adjustment. Results shows that 6 indicators of emotion regulation adjustment out of 14 used for the study did not significantly explain emotion regulation adjustment of early adolescents $(P>0.05)$, indigenous games greatly contributed to problem solving ability of respondents as $70.0 \%$ of them who had experienced of indigenous games portrait such ability against a significantly lower rate $12.2 \%$ for those not exposed $\left(\chi^{2}\right.$-test: $\left.\chi^{2}=160.190 ; d f=1 ; P<0.001\right)$.. Significant associations were observed between indicators of indigenous modes of socialization and among indicators of emotion regulation adjustment, suggesting that these constructs are better understood as multi-faceted, rather than unitary processes. Contributions of the study include an indigenous model of emotion regulation adjustment and the development of a culturally sensitive questionnaire of Emotion Regulation Adjustment. Thus there is need for the model to be tested in other cultural setting to determine its validity in measuring emotion competencies within cultural settings. The limited empirical work addressing the interrelations among indigenous modes of socialization and aspects of emotion regulation adjustment in early adolescent posed a significant limitation to the study. Larger studies using more diverse samples are needed to more clearly delineate relationships among components of emotional competence during early adolescent. Furthermore, further studies should address how the interrelations or lack thereof among components of emotional competence change as children mature.
\end{abstract}

Keywords: Indigenous Socialization Strategies, Emotion Regulation Adjustment and Early Adolescents

\section{INTRODUCTION}

Children grow up in a developmental niche as part of the broader culture. The socialization goals for emotion regulation aim to foster the development of culturally acceptable emotional behaviours which adhere to cultural values. The resulting cultural fit can be understood as cultural emotional competence (Friedlmeier \& Trommsdorff, 2002; Trommsdorff, 2007a). Research on emotion regulation and related concepts is usually based on Western studies, usually of adult (student) samples from WEIRD (Western, Educated, Industrialized, Rich, and Democratic) societies (Henrich, Heine, \& Norenzayan, 2010). Therefore, studying emotion regulation adjustment during adolescence in an indigenous setting should orient on new perspectives for socialization. Research in early adolescents peer relations provides evidence suggesting that social competence is a necessary construct for cultural adjustment across the lifespan (Parker, 1998). Specifically, children's social and emotional 
adjustments have been linked to social competence within the general peer group, as well as within friendship relations.

Theoretical assertions have associated the importance of healthy peer relations and social competence with social and emotional well-being in adolescence and later adulthood. Unfortunately, empirical investigation of this hypothesis is limited primarily to short-term longitudinal research across single developmental transitions (e.g. late adolescence to adulthood). The current study proposes to fill this gap with a long-term, follow-up study in which the developmental significance of social competence and problem solving skills will be assessed. Adolescence is a great opportunity for researchers to examine emotion regulation because of the physical, psychological, and social transformations that occur during this developmental stage. A major ability to adjust emotional developmental task involves acquiring for example, learning to regulate anger or frustration through peer interaction, modelling and guided participation which allows individuals to persist at tasks even when they encounter obstacles to their goals (e.g. in a school or during cultural activities). In contrast, there is little or no research particularly in Cameroon on how indigenous socialization strategies are directly linked to early adolescence emotion regulation adjustment. The emotion self-regulation ability of early adolescents thus has not been examined systematically in previous studies. This existing gap in literature motivated the conception of this study. This study aimed to examine the interplay among specific indicators of indigenous strategies of socialization such as indigenous proverbs, and indigenous games) within an eco-cultural setting which dictate emotion regulation adjustment with ardent attention on social competence and problem solving through an indigenized conceptual model of the Nso people of Cameroon. Thus social competence and problem solving skills are the main indicators of Emotion regulation adjustment that this study focused on.

\section{BACKGROUND OF THE STUDY}

Cultural heritage is disappearing from many Cameroonian communities often due to rapid changes in their lifestyle which is also hindering the process of transferring knowledge from the elders to younger members of the community. According to Lukong (2011) there are four main factors that are contributing to the extinction of Cultural Heritage in Cameroon especially among the Nso people: 1) Local communities have not been sensitized to know how important is the knowledge they possess as they consider their own cultural heritage as backward and as a hindrance to them in accessing economic wealth; 2). Many communities do not know how to go about identifying and protecting their knowledge systems; 3) There are no specific national laws that help communities protect their knowledge systems in a way that reflects their traditions and customs; 4) The deterioration in the use of indigenous languages in everyday conversation. As signatory to the UNESCO Convention for the safeguarding cultural heritage (2003), Cameroon is now required by Article 12 (section 1) of the convention to undertake an inventory of all the cultural heritage sites present in the country, which should be regularly updated. For this reason, there is need to map out existing types of cultural heritage in Cameroon to know their status and initiate measures for protection and enhancement. More significantly, Cameroon's many ethnic groups have a well developed and sophisticated folklore which embodies their history, traditions, world view and wisdom. Their legends recount the movement of people to and from the rift valley, into the highlands, the grasslands and the lake regions to their present settlements (Argenti, 2010).

The African continent is culturally complex and fluid with diverse cultures, natural environment and different ways of living, but sub-Saharan Africa is generally known for its rich oral traditions and proverbs which are the most widely and commonly used in this tradition of oral arts (AsimengBoahene, 2010; Grant \& Asimeng-Boahene, 2004). Cultural value orientations concerning interpersonal relationships and emotions help to create and enforce norms concerning emotion regulation, which in all cultures serve the purpose of maintaining social order Argentti, (2010). Personality and early experiences with caregivers lay the foundations for interpersonal relationships, and adolescence is the time when individuals first begin to test the stability of this foundation by establishing significant relationships outside of the family (Furman \& Buhrmester, 1992). An adolescent's success in these new relationships is rooted in his or her ability to regulate emotional experiences, even as he or she spends increasing time away from direct contact with the caregivers who, in ideal circumstances, provide the foundations of emotion regulation.

Historically, there has been much debate about the function of emotions. For example, Hebb saw emotions as neural activation states without a function (Hebb, 1949). However, recent research 
provides evidence that emotions are functional (Damasio, 2000). Emotions have a facilitating function in decision making (Oatley and Johnson- Laird, 1987), prepare a person for rapid motor responses (Frijda, 1986), and provide information regarding the ongoing match between organism and environment (Schwarz and Clore, 1983). Emotions also have a social function. They provide us information about others' behavioural intentions, and script our social behaviour (Gross, 1998). Social functions of proverbs include (1) explain human behaviour, (2) serve as a guide for moral conduct, (3) explain social behaviour, (4) serve to ensure or criticize conduct, (5) give shrewd advice on how to deal with situations, (6) express egalitarian views, and (7) express finer human qualities or emotions, such as generosity. Thus, proverbs serve as a basic teaching tool and a fundamental means for approaching life for the oral culture.

In the past two decades, psychological research has started to focus more on emotion regulation (e.g., Gross, 1998, 2001; Ochsner and Gross, 2005; Thompson, 1994). In brief, emotion regulation is the process humans undertake in order to affect their emotional response. Recent neurological findings (such as bidirectional links between limbic centres, which generate emotion, and cortical centres, which regulate emotion) have changed the consensus that emotion regulation is a simple, top-down controlled process (Gross, 1998). Emotion regulation is defined "as the process of initiating, avoiding inhibiting maintaining, or modulating the occurrence, form, intensity, or duration of internal feeling states, emotion related physiological, attentional processes, motivational states, and/or behavioural concomitants of emotion in the service of accomplishing affect-related biological or social adaptation or achieving individual goals" (Eisenberg \& Spinard, 2004, p. 338). These researchers highlighted the fact that children's effortful control, children's emotion regulation is common in developmental research. Effortful control has been found to be a measurable key component of emotion regulation (Eisenberg \& Morris as cited in Balter \& Tamis, 2006). Interest in emotion regulation has a long history, yet the field only began to emerge as an independent field of scientific study in the last decades of the 20th century (Gross, 1998). Since then, the field has grown exponentially, as is evident in the number of scientific publications, books, conferences, and training programs that are now devoted to the topic. The field of emotion regulation is no longer emerging, it is maturing. This maturation brings with it a shift. Different questions come into focus, novel questions arise, and different challenges come to the forefront. This special section reflects the shift that is taking place as the field matures.

Early contributions to the field of emotion regulation originated in the developmental literature (Campos, Campos, \& Barrett, 1989), and were quickly pursued by research in the adult literature (e.g., Gross \& Levenson, 1993). Research on emotion regulation has continued somewhat independently within these two traditions since then (Gross \& Thompson, 2007). This disconnect may have been due, in part, to the fact that, within each tradition, researchers were working on establishing emotion regulation as an independent topic worthy of attention. Several decades of research have resulted in an impressive body of knowledge and a deeper understanding of the nature of emotion regulation (Nyklicek, \& Denollet, 2008). This ripening of the field carries with it two important implications. First, there is no longer doubt that emotion regulation has important consequences for health and adaptive functioning. Instead, the field is now ripe for bridging different perspectives by uncovering and evaluating the basic assumptions that are guiding each perspective. Since emotion regulation concerns the regulation of emotion, any theory of emotion regulation is necessarily derived from basic assumptions about the nature of emotion. Such assumptions dictate the conceptualization of emotion regulation and the research questions that follow (Campos et al., 1989). To facilitate progress and integration, it is important to explicitly identify core assumptions about the nature of emotion and understand how they shape different programs of research in the field.

Second, research on emotion regulation is no longer a subsidiary of research on emotion. Instead, research on emotion regulation now holds the promise of informing our understanding of emotion. As research in the field becomes more integrative and interdisciplinary it could potentially test assumptions about emotion. To illustrate the two points highlighted earlier, A large proportion of adolescents suffer different maladaptive problems such as depression (Kessler \& Walters, 1998), suicidal attempts (Benton, 2003), aggressiveness and antisocial behaviour (Straus, Gelles, \& Steinmetz 1980. There is a clear and well established relationship between parental behaviours during their children's childhood and early adolescence and their children's maladjustment during late adolescence (Anderson, 2005). Children's emotional competence is a key skill-set in early 
adolescents, supporting children's development of social skills and affecting their risk for maladjustment. Emotional competence in early years consists of children's ability to express and regulate emotion consistent with cultural or societal expectations and children's ability to understand the causes and consequences of their own and others' emotions (Camras, \& Witherington, 2006). Social competence in early adolescents is best understood as children's ability to engage in social interaction, attain social goals, make and maintain friendships, and achieve peer acceptance (Rubin, Bukowski, \& Parker, 2006). Emotional competence underpins children's social competence in that successful social interaction and friendship formation requires that children express and regulate their emotions appropriately while applying their knowledge of emotions to respond properly to peers' emotions and behaviours (Denham, 1990).

Conversely, delays or disruptions in early adolescents' development of emotional competencies have serious, negative implications for children's transition to peer contexts like college (McCarthy \& Chabay, 2000). Children with poor emotional competence and who lack social skills have more difficulty forming peer relationships and benefit less from the educational environment of school than do children with stronger emotional and social skills (Foster \& Hester, 2000). A growing body of evidence suggests that children's emotions and emotion-related processes influence emerging social competencies and emotional/behavioural maladjustment. For instance, socially competent children demonstrate appropriate levels of positive affect during social exchanges, and such positive affect facilitates the initiation of social exchanges and friendship formation (Denham et al 1990). Additionally, children who are able to adaptively regulate negative emotions and balance their expression of positive and negative affect maintain social relationships better (Fabes \& Eisenberg, 1992) and are viewed as friendlier, less aggressive, and less sad by their teachers (Denham \& Burger, 1991).

Emotionally competent children also are better liked by their peers (Denham et al., 1990) and are more likely to respond pro-socially to peers' emotions In contrast, children who experience difficulties controlling their expression of negative emotion tend to have difficulty managing their anger during conflict situations, making them poor play partners (Denham et al., 2003). Likewise, children who express high levels of negative emotions are rated by teachers as less socially competent and are more likely to experience peer rejection (Denham et al., 2003). Clearly, children's emotions and emotional competence play a significant role in their relationships with peers. Parents all over the world hold specific beliefs about proper care and handling of children (Bornstein, 1989; Munro, 1975; Pomerleau, Malcuit, \& Sabatier, 1991; Shweder et al., 1998). These parental ideas (Goodnow, 1992) or parental ethnotheories (Super \& Harkness, 1996) may be assumed to express conceptions on the nature of children, parenting, and development, specifying how to become a competent adult in a respective environment (Deeds \& Chung, 1999). Thus, ideas about childcare practices are related to developmental goals (LeVineMiller \& LeVine, 1992). Although inter-individual differences are prevalent with respect to parenting goals and practices in every culture (LeVine et al, 1994).

Moreno (1996), nevertheless, suggested that members of cultural communities may be viewed as groups of individuals who co-construct a shared reality in different domains of life (Harwood, Schoelmerich \& Schulze, 2000). In particular, the conceptions of individualism and collectivism as cultural normative dimension (Hofstede, 1980; Kagitcibasi, 1997). Independent and interdependent construal's of the self as individual value orientations (Markus \& Kitayama, 1991) are understood by developmentalists as specifying different developmental goals which are correlated with different socialization contexts and parenting styles during different stages of development (Shweder et al., 1998). Parental ethno-theories may thus be conceived of as the mediating links between these cultural meta-models and behavioural contexts and practices (Harkness et al., 2000). It may therefore be expected that cultural communities who differ with respect to these value orientations also differ with respect to the nature of parental ethno theories. Differences in cultural expectations for the timing of developmental milestones have further supported differences in the attention to behaviours which may be related to independent and interdependent value orientations (e.g. an early focus on cognitive achievements as compared to an early focus on social achievements; autonomous as compared to symbiotic relational orientations; Rothbaum et al., 2000; Shweder et al., 1998.

Culture provides meaning to intended and to actually demonstrated behaviours and its consequences including emotional responses; these interpretations affect future behaviour orientation. The main features of culture are a homogeneous set of shared values, norms, and beliefs. Since time 
immemorial indigenous knowledge systems (IKSs) were used by societies in Africa and the rest of the world for various purposes, depending on the needs of the society in question. Until recently, IKs were colonized by other knowledge's from outside indigenous communities. In Sub-Saharan Africa, the advent of colonization brought in foreign knowledge's, the so-called "scientific knowledge" that denigrated IKs as unscientific, untried and untested for education and social development. African tribal groups are historically oral societies, where verbal modes of communication help people to point to what they meant and say what they could not put into written word. Theirs is a world where sounds carry ideas and images without any other intermediary in the process of communication. They picture ideas and images vividly in their mind's eyes rather than through letters and written words. This shows that the world of "orality" is a world of talk.

One strong underlying factor behind the African oral custom has to do with the fact that the origins of most of the African tribal groups are involved in obscurity. As such, the commonly received accounts are for the most part purely legendary. Also, many of their languages were unwritten and all that is known is from traditions carefully handed down through traditional historians, who are family members and functioned as historical storage and transmission. In a typical African family, the elders would gather the young people and children around the fireplace at night and narrate the stories, histories, and events that made them a proud and memorable people. Through these verbal arts, Africans transmit their beliefs, heritage, values, and other important information. So among the Africans, these forms of verbal arts are extremely important and effective means of communication, which have provided the following generations with wisdom. In every cultural community, parents want to pass on strategies that will promote the survival of their children and foster their cultural competence (Keller, 2003, 2007). Socialization strategies embody cultural curricula (Nsamenang, 1992) that represent the accumulated knowledge of prior generations within that environment. Socialization strategies are hierarchically patterned.

The most abstract level consists of socialization goals that express the developmental achievements that parents aim at, such as becoming an autonomous, self-reliant individual and/or becoming a socially interrelated person who is able to maintain harmony in their relationships. Socialization goals are translated into a system of parental ideas beliefs (Cheah \& Chirkov, 2008), or ethno theories (Super \& Harkness, 1996). These ideas are expressed in behavioural strategies, consisting of contexts or activity settings with actual behavioural interactions and communications. To understand emotional regulation adjustment in cultural context, we need to compare environments that differ in eco-social characteristics and reproductive strategies. It is assumed that different environmental conditions are represented in different cultural models. We expect that these differences are expressed in different socialization strategies of emotion evaluation with consequences for children's development of emotion regulation. The study describes the Nso eco-social environment. The Nso eco-social context is represented in traditional farming villages' void of-Western world experiences of technological advancement. The economy is subsistence based with little economic diversity among families and clans. The population is small scale, with person-to-person interactions in a dense social network. Formal education, if at all available, is basic. Lifestyle is characterized by hierarchical family systems based on age, gender and communal work. Reproduction starts early and comprises of many offspring (Keller, 2007).

The Cameroonian Nso farmers represent such a traditional farming community. The average rural Nso family consists of about seven members with about three living children ((Keller, 2007). Mothers' age at first birth is between17 and 20 years (Argentti, 2010). Mothers have about seven years of formal education with fathers sometime seven less (Keller, 2007; Yovsi, 2003). Nso people are governed by Cameroonian national authorities but also reined by their own traditional rulers, who are organized along a strict hierarchy with the "Fon" representing the highest local authority. Religious and philosophical concepts have their place within Nso traditional worldviews. Cosmovision, to a large extent according to a typical Nso indigene, dictates the way land, water, plants, humans and animals are to be used. It also prescribes how inhabitants are to behave, how decisions are taken, problems are solved. and how rural people organize themselves in meeting community goals. Obviously Christianity, Islam and western education have influenced the cosmovision of the Nso people especially those with formal education. For the Nso people in the North West region of Cameroon, the human world, the natural world and the spiritual world are linked. 
The natural world provides the habitat for the spirits and sends messages from the spiritual world to the human world. The spiritual world provides guidance, punishment and blessing to the human world. People therefore have to relate to both the natural and the spiritual world. Indigenous knowledge is thus intertwined with the Nso cosmic notion and adherence to their cultural values.

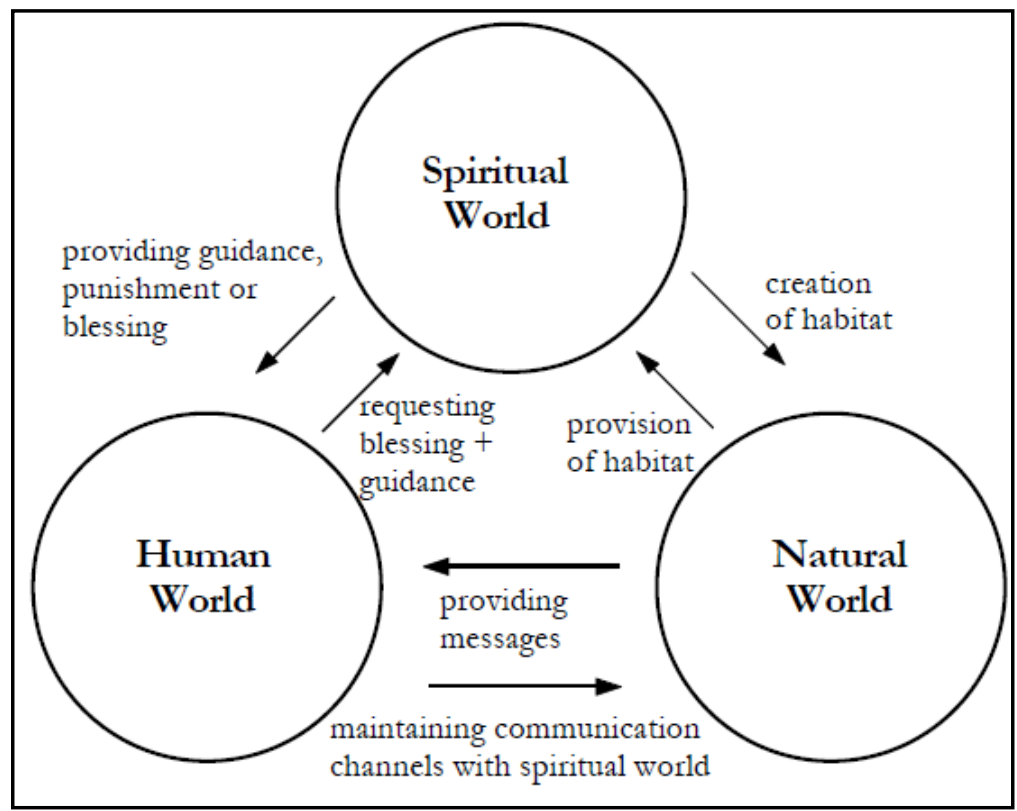

Figure1.0. The Nso Cosmovision

Source: T. E. Lukong (developed from elders' explanation of Nso cosmic order).

According to the Nso people, the spiritual world (Gods, spirits, ancestors), the human world (including spiritual and political leaders), and the natural world (sacred groves, ritual crops and animals, food items and cash crops) are interrelated. Often a hierarchy between divine beings, spiritual beings, men and women, and natural forces are frequently indicated (see figure 1.0). These cosmovisions give rise to several rituals in which elders, priests, soothsayers and spiritual leaders play a prominent role. This explanation is related to this study in that, virtually all principles and ways dictated by such natural rules as handed down from generation to generation shape not just parenting qualities, but also how children need to behave relate with one another in a peaceful manner. Emotions are closely interwoven with experiences, evaluations, and regulations of self, relationships, and situations. Thus, the socio-cultural context constitutes the meaning and the expression of emotions (Markus \& Kitayama, 1991. The expression of positive emotionality can consequently be understood as the foundation of individual uniqueness and independence. Emotional neutrality and control of emotional displays, on the other hand, can be understood as the instantiation of social relatedness and interdependence. We therefore regard the expression of positive emotionality as a vital part of a socialization strategy toward autonomy. We expect that the expression of emotionality is not supported as a valued behavioural expression in the socialization strategy toward relatedness.

The interrelated value orientation that has been developed mainly with respect to East Asian cultures (Markus \& Kitayama, 1991) has also been identified in traditional rural areas across other parts of the world (Kagitcibasi, 1996, 1997; LeVine et al., 1994). Also traditional African cultures in general (Lancy, 1996; Zimba, 2002) and the cultural community of the Nso in Cameroon in particular (Nsamenang, 1992; Nsamenang \& Lamb, 1994; Tchombe, 1997; Yovsi, 2001) have been described in terms of a high appreciation of interrelatedness in their conceptions of relationships and competence. The documentation of family life and socialization patterns among the Nso cultural community reflects a high esteem of harmonious and hierarchically organized relationships between family members and a wide social reference group, mostly the village. Childcare is aimed at instilling acceptance of the moral authority of parents and obedience (Yovsi, 2001). Compliance, conformity, and respect are the major socialization instructions (Yovsi \& Keller, 2001). Mothers, especially primiparae, are often taught basic child psychology by elderly and experienced women or by their mothers-in-law. These instructions range from spiritual communication to health concerns, when, for example, body movements, especially during sleep, are believed to express messages from the ancestors identifying specific signals of illnesses. 
The infancy or 'wan' period sees the child under the strict surveillance and overprotection of the mother, siblings, grandmother, and other family and community members. The child undergoes traditional rituals as he or she proceeds through infancy (e.g. burial of the placenta, ritual messaging, bathing and oiling) which is believed to influence the life of the child and the mother. The infant is carried almost the whole day on the lap, back and loins of his or her caretakers and co-sleeps with the mother and the other siblings. A special sensitivity exists towards negative signals of the child which are attended to immediately, mainly with breastfeeding. A major focus is being laid on motor stimulation which is supposed to contribute to the development of muscle strength and early achievement of motor milestones (Yovsi \& Voelker, 2002; Super, 1981). Early motor competence is considered to support children's responsibility training enabling them to contribute early on to the subsistence of the family by performing daily chores. From an African point of view, a sense of self is only attained through the community in terms of being interconnected and enacting one's social role (Nsamenang, 2006). Identity is defined in terms of status in lineage, clan, and community (Mbaku, 2005). Development is interpreted as the acquisition and growth of competencies required to fully engaging in society and family life. Children are expected to assume social responsibility as a primary value and children's competencies are defined in accordance with their social maturity. Intelligence is conceived as responsibility and social maturity, not an abstract, cognitive ability (Nsamenang, 1992b).

The majority of the Nso can be considered to represent a typical non-Western society, following an interdependent cultural model aiming at interconnecting individuals in the community. However, influences of the Western world are found in various domains as well. Whilst it is plausible to treat the Nso as a community extremely different from Western societies, it is at the same time necessary to take a careful look at variances within the Nso community. Social changes due to modern globalization seem to have had an impact on the traditional family structure and gender roles. Shifting observed and described by Mbaku (2005, p. 167) are a decrease in family size, an increase in female participation in the labour market, the emergence of new childrearing patterns influenced by Western ideas, and accelerated migration from rural to urban areas. The older generation believes that children should be seen but not heard, i.e. not question parental advice. The younger generation of Nso parents admit children to be seen and heard, i.e. they allow children to have an own opinion. In less than ideal developmental circumstances, emotion regulation may fail to develop adequately, and adolescents may find themselves in states of periodic or chronic dys-regulation that are implicated in adolescent internalizing and externalizing problems. Morris and colleagues (2007) proposed a theoretical model that grounded emotion regulation between developmental circumstances and adolescent adjustment.

Specifically, they emphasized the importance of emotion regulation as a mediating factor between multiple aspects of adolescent development (e.g. adolescent temperament, parenting, attachment, and observational learning) and adolescent adjustment (including internalizing and externalizing symptoms; Steinberg, 2007). Emotion regulation has been described as a complex, multifaceted phenomenon which develops through the integration of several behavioural and biological processes (Thompson \& Goodwin, 2007). It involves intrinsic and extrinsic processes that operate to monitor, evaluate and modify emotional reactions, especially intensive and temporal features, to accomplish one's goals. Intrinsic and extrinsic processes can be thought of as physiological, cognitive, behavioural, and social human processes, that represent individual response domains within an individual or in connection to his/her environment (Garber \& Dodge, 1991). Therefore, the terms processes and domains within the emotion regulation framework become interchangeable. A number of theories address early adolescents' socio-emotional development, but for the purpose of this study, theoretical framework was drawn from three main theories, that is emotion regulation theory (cross, 2001), Developmental Niche Theory (Super \& Harkness, 1986) and the socially constructed child theory. These three theories were chosen based on their inclusive trends of addressing the social contexts in which children develop and major changes in children's socio-emotional development which has a direct implication on adolescence emotion regulation patterns.

\section{Statement of the Problem}

Observation shows, there has been a general decrease in the use of indigenous traditional proverbs, games and play songs in both rural and urban communities in Cameroon. The communities rather prefer the use of English games and play songs through the use of emerging technological devices such as laptops, computers, etc. The non-use of traditional games in the schools results in learners 
missing out and running the risk of not being conversant with what their culture can offer. Children play these games alone at home or at school during break times. Children then lack guidance on the role of these games. Children no longer sit in the evening for proverbs and tales by moonlight that promotes the values of respect, integrity, peace, love and unity. It has been neglected in the rural areas where this sort of environment would fit best. The neglect of such cultural tools for knowledge transmission is a threat and could result to total disappearance of cultural values attached to these indigenous modes of socialization. These unique indigenous games provide an interlude activity, which can easily be adapted to learning situations. In addition, there is readily available equipment for use during the game, as well as easy to- follow learning procedures. Games and play are learnt and done for the sake of living a perfect life: to be able to express joy and self-amusement. Through these traditional games, children are able to aesthetically display and express themselves emotionally. Indigenous games enhances self-expression, collaborative skills, humility, collective identity, collective consciousness and the sense of togetherness through teamwork which are vital indicators of good and acceptable emotional behaviours. All these aspects are important in human development for they boost the development of self-concept, self-esteem, self actualization and self-confidence in the participants especially in adolescent boys and girls. Consequently, early adolescents face cultural difficulties in understanding cultural values and morals attached to these indigenous modes of socialization. These cultural strategies are vital tools for adolescents to develop capacity to feel positive about themselves, develop capacity to interact successfully with others, develop capacity to recognize, express and regulate feelings. This research is thus an attempt to salvage and preserve the continues utilization of indigenous modes of socialization such as proverbs and indigenous games for they greatly enhance emotion regulation adjustment amongst adolescents

\section{OBJECTIVES OF THE STUDY}

\section{General Objective}

The current study aims to examine the influence of indigenous modes or strategies of socialization on Emotion Regulation adjustment of early adolescents.

\section{Specific Research Objectives were;}

- To identify how proverbs influence emotion regulation adjustment.

- To examine how indigenous games influence emotion regulation adjustment.

- To Determine if there are gender difference in emotion regulation patterns among early adolescents

\section{REVIEW OF RELATED LITERATURE}

The study asserts that the skills, attitudes and values learnt through indigenous proverbs, traditional games and play prepare the adolescents to take up their adult roles in appropriate emotional dispensation guided and accepted by cultural values. They would learn mainly from peers at home during free time through the process of socialization with the same age cohort. The song play game provides interactive apprenticeships between the old and young, which the learners are guided to learn and perform. Such games provide for girls and women's own space, which is important for the development of gender roles socialization processes among the female folk. This situation is no longer common in most societies, especially due to urbanization. Participation in the traditional game by the youths ensures continuity of indigenous recreational activities as part of cultural inheritance. Emotional development has long been neglected in the study of psychological concepts. Two factors could account for this: one is the conviction that emotions are epiphenomenal in nature and another is the difficulty with the measurement of the construct (Saarni, Mumme, \& Campos, 1998). However, in the past 25 years, a revival has taken place and a large amount of evidence has accumulated to support the scientific validity of emotions as a construct (Sarrni et al., 1998; Cole et al., 2004) and advances have been made in measurement. This Chapter focused on three main areas, the conceptual, empirical and theoretical frameworks. Conceptual framework critically examined main concepts of the study, theories related to the present study were also critically reviewed to give substance to results while previous studies relating to this study were equally reviewed to show case how the results differ or are similar to pass research based on the present investigation. This review of literature provides the necessary background for justifying the imperativeness of the present study. 


\section{Conceptual Review}

\subsection{Indigenous Strategies of Socialization}

The term 'indigenous' describes specific groups of people who are grouped under the criteria of ancestral territory, collective cultural configurations, and historical location. Indigenous modes of socialization is the local strategies/knowledge, knowledge that is unique to a given culture or society. Cultural ways of socialization contrasts with the international knowledge system generated by universities, research institutions and private firms. It is the basis for local-level decision making in agriculture, health care, food preparation, education, natural-resource management, and a host of other activities in rural communities. (Warren, 1999). Indigenous information systems are dynamic and are continually influenced by internal creativity and experimentation as well as by contact with external systems" (Flavier, de Jesus, Navarro \& Warren, 1999). The commonality in these definitions is that Indigenous strategies of socialization have utility value in indigenous communities. They are experiential and address diverse and complex aspects of indigenous peoples and their livelihoods. In the process of generating Indigenous knowledge, indigenous people take into account their cosmos, spirituality, ontological realities, land, socio-cultural environment and historical contexts. Indigenous moods of socialization, such as proverbs, folktales, legends, indigenous games etc are transmitted, maintained and retained within specific cultural sites for education and sustainable development.

Sociology is based on the precept that the human being is a social animal. But a newborn child is a biotic entity though not yet a social being. The curiosity is about how a human newborn rapidly transforms from a biological system to become a social being? The process by which the human organism is humanized into a social being or is transformed from its animal state into a mature social being or cultural agent is called socialization. Social interaction is at the centre of this process. By social interaction we mean the process of being aware of others when we act, of modifying our behaviour in accordance with consideration of others or their view of us. Social interaction occurs in Variety of ways and its patterns are complex, for instance, between people. say husband and wife, siblings, classmates, peer group member\& acquaintances or strangers on the street, and among members of organizations or institutions. Socialization entails the learning of expectations, habits, values, beliefs, and other skills and requirements necessary for effective participation in social living. That is, socialization involves being taught all the things a child needs to increasingly function as member off a specific society: In this sagacity, socialization is "the process by which a individual becomes a member of a particular culture and takes on "values, beliefs, and other behaviours in order to function within it." It is through the process of socialization that society teaches desirable behaviour while inhibiting undesirable ones, prepares individuals to become successfully functioning members in its principal institutional settings or agencies such as the family, school, community, religion, and the workplace. Every society specifies certain outcomes or ranges of outcomes of socialization. For example, every society engages some of its resources to produce children who will be law-abiding and responsible adults.

Cross-cultural research findings over the past several decades have extended our understanding of socialization. Thus, contemporary theories of socialization place greater stress on the interactive exchanges between parent and child as contributors to behaviour. In addition, explanations have become more complex and multidimensional than those offered by earlier approaches. Indeed, socialization theories have undergone substantial revision as theorists and researchers recognized the cultural limitations or ethnocentrism of the theories. For instance, they claimed that explanations of behaviour in one society applied equally well in others. A scholar who has contributed significantly to our understanding of socialization, particularly in the area of cognition, is Barbara Rogoff Her book "Apprenticeship in thinking "(1990) is a landmark in the field Rogoff's approach to this topic was influenced greatly by the work of the Soviet psychologist, Lev Vygotsky, on culture and cognitive development. Both vygotsky and Rogoff invoke the term guided participation to emphasize the bidirectional (two-way) nature of socialization and the fact that children are active participants in their own socialization.

Nsamenang's book, Human development in cultural context (1992) and the theoretical approach to development that it promotes is worthy of consideration for interventionists, teachers and educators for it brings to light the affective fervour of the environment on the child's cognitive and social development. John Ogbu (1994) has written a powerful article articulating the significance of the 
child's 'frame of reference to his learning potentiality. Nsamenang's eco-cultural theory echoes some of what Oghu says, to the effect that "Children are socialized to acquire cognitive skills or patterns of intelligence that exist already in their culture because their culture requires it; it is functional in the culture. Socialization is an intermediate variable, a means or formula through which people transmit that which already exists in the culture" (Ogbu. 1994).

\subsection{Cultural Values and Emotion Regulation Norms and Dynamics}

Because one of the major functions of culture is to maintain social order, cultures create rules, guidelines, and norms concerning emotion regulation because emotions serve as primary motivators of behaviour and have important social functions (Keltner et al., 2003). Previous studies, in fact, have documented a number of cultural differences in processes related to emotion regulation, such as emotion-related appraisals (coping, which is related to Reappraisal (White, \& Lehman, 2004); and display rules, which are related to Suppression (Hirayama, \& Petrova, 2005). Cultural value orientations concerning interpersonal relationships and emotions help to create and enforce norms concerning emotion regulation, and norms concerning emotion regulation in all cultures serve the purpose of maintaining social order. Cultural differences in value orientations, therefore, should be associated with differences in mean levels of emotion-regulation norms. Individualism, Egalitarianism, and Affective Autonomy, for instance, should be associated with more Reappraisal and less Suppression because these cultures value emotions more and encourage their freer and open expression.

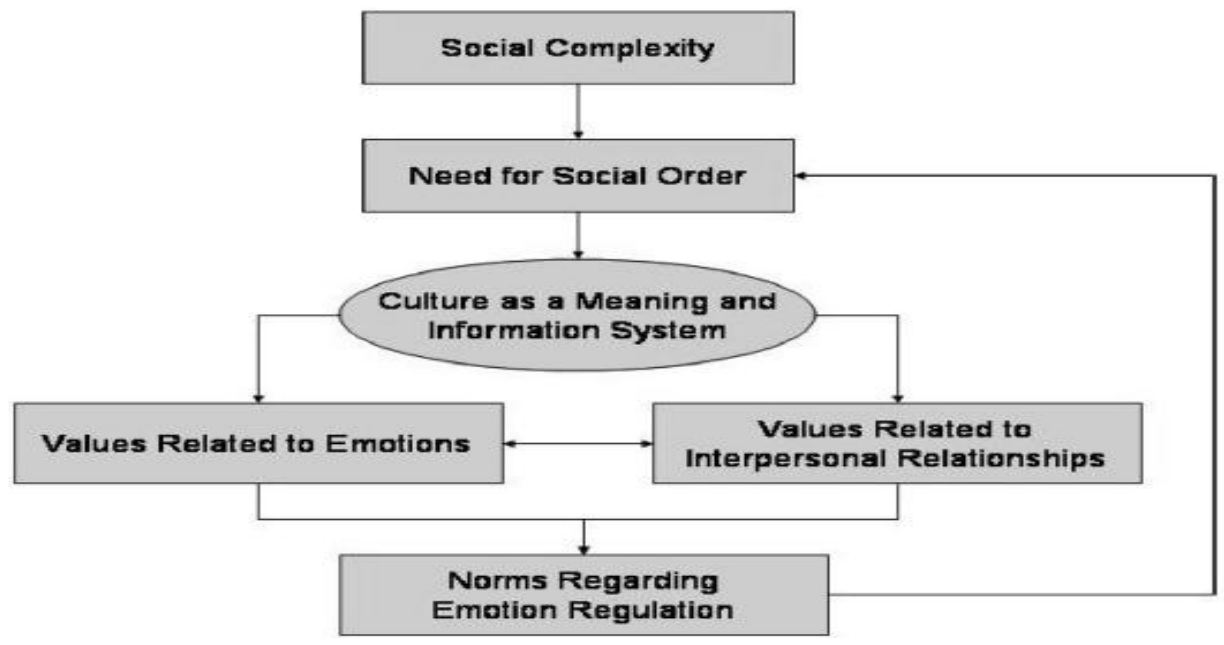

Figure2.0. a functional view of the relationship between cultural value orientations and emotion regulation.

Source: David Matsumoto (Culture, Emotion Regulation, and Adjustment)

Uncertainty avoidance and long- versus short-term orientation should be associated with less reappraisal and more Suppression because these cultures generally regard emotions as dangerous and threatening to a longer-term perspective on interpersonal relationships. These cultural differences in emotion regulation norms should serve the function of maintaining social order in a culturally appropriate fashion.

Cultures can differ not only in the strength of the norms (evidenced by means) but they can also facilitate different functional relationships between them. In Gross and John's (Gross \& John, 2003; John \& Gross, 2004) research, reappraisal and suppression were orthogonal factors in American students. This may or may not be the case in other cultures. There is ample theoretical reason to believe so. Suppression and reappraisal are two (of many possible) strategies that individuals may engage in order to regulate emotions. For instance, on the individual level, it may be that Suppression, at least initially, may provide individuals with the time to reappraise the events that elicited emotion in the first place and to evaluate the "proper" response, given the cultural meaning of the particular context in which the emotion is elicited. Alternatively, it could very well be that reappraisal occur first, thus driving Suppression. Clearly a correlation between these two variables cannot determine causal paths. But Suppression may be positively associated with reappraisal in cultures with a greater need to maintain social order; these would include cultures high on Power Distance, embeddedness, hierarchy, uncertainty avoidance, and long-term orientation. A positive relationship may also suggest greater overall need for emotion regulation as a whole. The relationship between Reappraisal and 
Suppression may be lower or even negative in cultures high on Individualism, egalitarianism, or affective Autonomy. In these contexts, reappraising emotion-eliciting situations should lead to greater expression, congruent with cultural norms related to the importance and expression of emotion. Thus, cultures high on Individualism, Affective Autonomy, and Egalitarianism should be associated with a negative relationship between reappraisal and suppression. This relationship may also be indicative of these cultures' overall needs to regulate emotions less.

\subsection{Emotional and Social Competence}

Emotional competence refers to the ability to display emotions in a socially, culturally, and situationally acceptable manner, to understand one's own and others' emotions, and to inhibit the experience and expression of emotion when necessary to achieve personal goals in a socially acceptable manner (Denham \& Grout, 1993; Eisenberg et al., 1998a). Saarni (1999) has proposed that parental emotion socialization affects children's expression of emotion through cultural and societal expectations and norms; children learn guidelines and rules for when, where, and to which people they should express different emotions. Beliefs about which emotional expressions are socially acceptable or desirable are called display rules; within each culture and society there is considerable consensus for when and how expressions of different emotions should occur (Saarni, 1999). Saarni suggests that children learn these display rules through the process of parental emotion socialization. Understanding one's own and others' emotions also develops as a result of the parental emotion socialization process. This process involves reflection on one's own emotional experience as well as the ability to infer others' emotional states based on their emotional expressions (Saarni, 1999). The ability to infer others' emotional states is a crucial skill that helps children effectively initiate and maintain social relationships (Denham et al., 2003). Emotion regulation is an important component of emotional competence. Emotion regulation is defined as the ability to monitor, evaluate, and modify one's own emotional experience or emotional expression in accordance with the demands of the current social environment (Thompson, 1994). Emotion regulation involves the ability to alter the intensity, escalation (e.g., latency and time to rise), and duration of an emotional response (Thompson, 1994). Emotion regulation is used to alter these emotional responses in a way that fits the individual's goals for the social situation they are in (Thompson, 1990). That is, effective emotion regulation requires the ability to understand display rules and to make decisions regarding when and where to express specific emotions, as well as the ability to identify and effectively implement strategies for increasing or decreasing emotional arousal (Thompson, 1994).

These skills are all required to demonstrate emotional competence, and they are all believed to be acquired through parental emotion socialization (McDowell, Kim, O`Neil, \& Parke, 2002). In sum, emotional competence involves the understanding of society's display rules, an ability to understand one's own and others' emotional experiences, and the development of the skills that are necessary to regulate one's own emotions. Each of these skills is believed to play a part in the development of social competence. Children who understand others' emotions and who can identify their own emotions and regulate them in a way that is socially acceptable are more likely to be able to engage in successful social interactions with others (Denham et al., 2003). Social competence is defined as the skills that help children engage in successful social interactions, such as social skills, prosocial behaviours, social play behaviour, and socially appropriate behaviour (Trentacosta \& Fine, 2010). Four types of social skills are believed to strongly affect children's degree of peer acceptance, ability to form positive relationships with teachers and other important adults, and ability to make friends: cooperation, assertion, responsibility, and self-control (Gresham \& Elliot, 1990). These four types of social skills are also valued and commonly rewarded in Western societies (Gresham \& Elliot, 1990). As such, they were a focus of the present study. Cooperation skills include behaviours such as helping others, complying with rules and directions, and sharing (Gresham \& Elliot, 1990). Assertion skills include initiating behaviours, such as introducing oneself, asking others for information, and responding to others' actions (Gresham \& Elliot, 1990). Responsibility skills include behaviours that show the children's ability to communicate with adults and show respect toward property, such as asking permission before using another family member's property (Gresham \& Elliot, 1990). Selfcontrol skills include behaviours that could occur in conflict situations, such as responding appropriately to teasing, as well as behaviours that could occur in non conflict situations that require compromising and taking turns (Gresham \& Elliot, 1990). 


\subsection{Adolescence Developmental Stage}

The developmental stage of adolescence occurs between the ages 11 and 22. For those individuals who, because of educational goals or other social factors, entry into adult roles is delayed, late adolescence occurs between the ages of 18 to 22 (Elliot \& Feldman, 1993). In most western countries adolescence is considered a period of increasing freedom, during which the principal duty is to acquire an education, and during which parent-child relationships are transformed while peer interactions acquire more importance (Elliot \& Feldman, 1993). This transformation, however, does not happen at the expense of the parent-child bond. On the contrary, the evidence indicates that most families enjoy warm and pleasant relations during the adolescent years (Steinberg, 1993). Prior research has shown that despite the fact that adolescents tend to have little interaction with adults, parental relationships with their children tend to maintain importance during adolescence (Grotevant \& Cooper, 1986). Furthermore, different studies show that parent-early adolescent relationships have consequences for late adolescents and young adults' adjustment (Anderson, 2005, Aronen, 2000). This evidence strongly supports the surveying of late adolescents about their prior relationships with their parents during early adolescence.

\subsection{Emotion Regulation Adjustment}

A major developmental task involves acquiring the ability to adjust emotional expressions to the demands of specific environmental contexts. For example, learning to regulate anger or frustration allows individuals to persist at tasks even when they encounter obstacles to their goals (e.g., in a school or work setting). Similarly, social interaction is likely to be more successful if individuals are able to modulate their emotional reactions (e.g., anger, fear, exuberance) when appropriate. In the last 20 years, research on emotion regulation has burgeoned. Studies examining potential influences on individual differences in emotion regulation indicate that parenting behavior is one factor that is related to children's emotion regulatory skills, although there are many others (e.g., child temperament). Furthermore, research indicates that individual differences in emotion regulation predict other important developmental outcomes, including social competence, internalizing and externalizing behavior problems, and academic achievement. In addition to these established associations between parenting behaviour and emotion regulation and between emotion regulation and children's adjustment, there is also substantial research linking parental behaviour to children's adjustment in a variety of domains.

The definition of emotion has been a topic of debate for many years and continues to be a source of disagreement among theorists (Cole, Martin, \& Dennis, 2004). However, there is general agreement that emotions have an evolutionary basis and were selected for over the history of our species because they were adaptive for survival. Emotions facilitate appraisal of the individual's environment and guide action or behavior. For example, if an individual comes in contact with a dog, their immediate response might be that of fear, which would cause them to run and hide. Perhaps because of theoretical disagreements about the nature of emotion, there is also some disagreement about defining emotion regulation. However, a definition provided by Calkins and Hill (2007) is generally consistent with current conceptualizations. Emotion regulation encompasses "...those behaviors, skills, and strategies, whether conscious or unconscious, automatic or effortful, that serve to modulate, inhibit, and enhance emotional experiences and expressions" (p. 229). For example, if a child cannot obtain a desired toy, shifting her attention toward something other than the toy could reduce her negative affect. Normative Development of Emotion Regulation In the contemporary literature, a lack of consensus regarding operational definitions of emotion regulation appears to have created challenges to researchers, and clinicians alike. However, several key theorists have offered their definitions of emotion regulation based on their understanding of emotion and related affective processes. Gross (2007) noted that emotion regulation impacts an individual's general experience with emotions: (a) what to feel, (b) when to feel, (c) how to feel, and (d) how to express oneself. Furthermore, he emphasizes that emotion regulation models require mechanisms for emotion reduction, enhancement, and maintenance a view held by most other theorists (Gross, 1998a). Gross proposed that the emotion regulation process can occur consciously or unconsciously. This particular view is also held by most theorists. For example, Koole (2009) refers to deliberate, versus "automatic and effortless" regulation in his conceptualization of emotion regulation. Gross and Muñoz (1995) also proposed two modules of emotion regulation: a) antecedent-focused emotion regulation and b) response-focus emotion regulation. These two modules of emotion regulation were introduced to researchers and clinicians in 
the early stages of contemporary research in emotion regulation. Antecedent-focus emotion regulation pertains to actions that affect whether a given emotion occurs. This form of emotion regulation involves modifying the external or internal environment, thereby modifying the input to the emotional system (Gross, 2007: Holodynski \& Friedlmeier, 2006). Response-focus emotion regulation occurs after emotion has already been activated.

\subsection{Measurement of Emotion Regulation in Empirical Studies}

Contextual and gender-related differences are also important variables to consider when measuring emotion regulation in children. However, there is a general lack of consensus among researchers regarding measurement methodologies, which may be related to differing working definitions of emotion regulation (Cole, 2004). These differences between studies in methods of measuring emotion overregulation are also a likely contributor to mixed results in the literature. Another challenge of examining emotion overregulation as a predictor of risk relates to the need for attending to developmental issues in measurement techniques. In order to assess the construct of emotion dysregulation in young children, methods of accurately measuring internal states first must be implemented. Older children and adolescents are often given self-report questionnaires or are asked to describe their expected emotional reactions to a series of hypothetical provocative situations (Gross, 2007).

However, most young children are not capable of accurately assessing, monitoring, and reporting their own emotions (Cassano, \& Adrian, 2007). In particular, studies have suggested that children below the age of six are not yet cognitively self-aware (e.g., Reynolds, 1990). Therefore, in children with less developed cognitive abilities, emotion dys-regulation is often operationalized by measuring patterns of emotional expression. One method for measuring children's emotional expression is using parent and teacher reports of child emotional behaviour. Given young children's difficulty in accurately reporting their own emotion regulation techniques, observation by adults who interact with them regularly is a common alternative. Parent questionnaires measuring child temperament are also important in assessing qualities related to emotion regulation abilities, such as behavioural inhibition. However, overregulated affective expressions may be underreported by adults, due to their more covert nature (Cole 1994). In addition, secondary-report rating systems such as parent and teacher questionnaires have been over-represented in studies of emotional expression and can provide a onesided view of children's behaviours (Zeman, 2007). Still, observations from parents and teachers are often valuable sources of children's daily behaviour (Prizmic-Larsen, 2006). Measuring emotion regulation abilities directly in young children, through observational means, would reduce reporting biases and thus improve the likelihood for an accurate assessment. Laboratory-based observations of behaviour have been used to measure regulation, such as clean-up tasks (Guidash, \& Wanna, 2002) but they tend to be relatively unstructured.

More structured tasks, such as laboratory tasks measuring temperament (Koenig \& Vandegeest, 1996), tend to capture temperament characteristics that are indirect measures of children's emotion regulation abilities. Saarni's (1984) Disappointment Task, which examines children's responses to disappointment, is one of the few structured, observational tasks for directly measuring negative emotion in young children so that individual differences in emotion regulation can be observed. Another measurement issue relates to the limited distinctions made between types of emotion regulation abilities. While some structured emotion regulation measures exist, there is a lack of agreement on operational definitions and a paucity of research examining the specific construct of emotion overregulation. Instead, the few existing studies often focus on related constructs, such as emotion inhibition and suppression. For example, a recent study by Keenan, Hipwell, Hinze, and Babinski (2009) examined children's self-report ratings of emotional expressiveness, as well as coded emotional expressions during a dyadic problem-solving task. .

\subsection{Why do People Regulate their Emotions?}

The majority of research on emotion regulation, however, particularly in the adult literature, still focuses on how regulation takes place rather than on why it takes place. Understanding why people regulate their emotions is crucial, however, because such motives determine the direction of regulation (Tamir \& Mauss, in press). Both Charland (2011) and Campos and colleagues (2011) mention that emotion regulation researchers typically assume that unpleasant emotions are undesirable, whereas pleasant emotions are desirable, but that this is not necessarily the case. Campos 
and colleagues (2011) argue that feeling better is rarely the desired end-state. Instead, consistent with the instrumental approach to emotion regulation described above, goals in emotion regulation typically involve attaining instrumental goals rather than hedonic ones (Tamir, 2009a). Thompson (2011) and Izard and colleagues (2011) similarly argue that emotion regulation is undertaken in the service of higher-order goals. These ideas have now received empirical support. Different people can be motivated to experience different emotions (Tamir, 2005, 2009b; Tsai, Knutson, \& Fung, 2006; Wood, Heimpel, Manwell, \&Whitting, 2009) and people can be motivated to experience different emotions in different contexts (Tamir \& Ford, 2009; Tamir, Mitchell, \& Gross, 2008). Asking what people want to feel is different from asking what people ought to feel. Several contributors to the special section, including Campos and colleagues (2011), Izard and colleagues (2011), and Thompson (2011), raise the issue of adaptation in emotion regulation. According to Charland (2011), attempts to define adaptive emotion regulation moves researchers away from scientific considerations and closer to moral ones. In his contribution, he cautions that emotion regulation necessarily involves a stipulation of desired end-states which is ultimately based on values. This, according to Charland, poses a challenge to emotion regulation research. His contribution also underscores the importance of considering philosophical and historical perspectives in emotion regulation.

\section{THEORETICAL FRAMEWORKS ON EMOTION REgULATION ADJUSTMENT}

An abundance of research investigating emotional processes over the past few decades has emphasized the critical role that emotions play in emotional well-being and daily functioning (Strongman, 1996). The shift of emotion research from defining and measuring emotions to examining multiple modes of emotional responding brought a resurgence of interest in regulatory aspects. Consequently, there has been a growing interest to understand the role of emotion regulation in overall well-being (Dodge, 1991). This section focuses on main theoretical perspectives used for the present study. The choice of these theories is because of their reflective contextual discussion on the subject matter under investigation which is emotion regulation adjustment.

\subsection{Gross' Emotion Regulation Theory (2001)}

Gross (2001) describes a process model of emotion regulation using the following definition: 'Emotion regulation includes all of the conscious and non conscious strategies we use to increase, maintain, or decrease one or more components of an emotional response' (Gross, 2001). Increasing components of an emotional response is called up-regulation of an emotion, and decreasing these components is called down-regulation of an emotion. The components he considers are (1) the experiential component, (the subjective feeling of the emotion), (2) the behavioural component (behavioural responses), and (3) the physiological component (responses such as heart rate and respiration). Humans use strategies to affect their level of emotional response for a given type of emotion, for example, to prevent a person from having a too high emotional or too low emotional antecedent-focused strategies and response focused strategies. Antecedent-focused strategies are applied to the process preparing for response tendencies before they are fully activated. Responsefocused strategies are applied to the activation of the actual emotional response, when an emotion is already underway. In his model, Gross distinguishes four different types of antecedent-focused emotion regulation strategies, which can be applied at different points in the process of emotion generation: situation selection, situation modification, attentional deployment and cognitive change. A fifth strategy, response modulation, is a response-focused strategy.

In theorizing Emotion Regulation by Gross (1998), the first antecedent-focused emotion regulation strategy in the model is situation selection: a person chooses to be in a situation that matches the emotional response level the person wants to have for a certain emotion. For example, a person can stay home instead of going to a party, because he is in conflict with someone who is going to that party. This is an example of down-regulating one's emotion (anger in this case). An example of situation selection to up-regulate one's emotion (excitement in this case) is taking a roller-coaster ride. The second antecedent-focused emotion regulation strategy in the model is situation modification. When this strategy is applied, a person modifies an existing situation so as to obtain a different level of emotion. For instance, when watching an irritating television program, one may zap to another channel. The third antecedent-focused emotion regulation strategy is attentional deployment. This strategy refers to shifting your attention to a certain aspect. For example, one may close his eyes when watching an exciting penalty shoot-out. The fourth antecedent-focused emotion regulation strategy is cognitive change: selecting a cognitive meaning to an event. A specific type of cognitive change, 
which is aimed at down-regulating emotion, is reappraisal: 'Reappraisal means that the individual reappraises or cognitively re-evaluates a potentially emotion-eliciting situation in terms that decrease its emotional impact' (Gross, 2001).

An example of reappraisal is a case when a person loses a tennis match and blames the weather circumstances, instead of his own capacities. However, note that cognitive change could also be aimed at up-regulating emotion. The fifth emotion regulation strategy, response modulation, a response-focused strategy, is applied after the emotion response tendencies have been generated: a person tries to affect the process of response tendencies becoming a behavioural response. A specific type of response modulation, again aimed at down-regulating, is suppression:' Suppression means that an individual inhibits ongoing expressive behaviour.'(Gross, 2001). An example of suppression is a person that hides being nervous when giving a presentation. In his article, Gross predicts that early emotion regulation strategies are more effective then strategies that are applied at a later time point in the process (Gross, 2001). He describes an experiment of which the results support this prediction. In this experiment, participants are shown a short film of a disgusting arm amputation in three different conditions: the reappraisal condition, the suppression condition, and the neutral condition. In the reappraisal condition, participants were asked to think about the film in such a way that they would not respond emotionally (for instance as if it were a medical teaching film). In the suppression condition, participants were asked to hide their emotional reactions to the film. In the natural condition, participants were given no specific instruction.

The results showed that reappraisal decreased emotion experience and expressive behaviour, and did not have an effect on memory, or the physiological response. Suppression decreased expressive behaviour, but had no effect on the emotion experience. Moreover, it impaired memory, and increased the physiological response. In this paper, our focus is on antecedent focused strategies (i.e., situation selection, situation modification, attentional deployment and cognitive change). Thus, the consequentfocused strategy response modulation is not considered. The main reason for this is that, according to Gross', this strategy is not very effective: it does influence behavioural and physiological responses, but does not affect experiential responses (Gross, 2001, p.216). Nevertheless, it would not be difficult to incorporate this strategy in the computational model, by treating it in a similar manner as the antecedent-focused strategies. Cognitive-Behavioural Therapies have the purpose to facilitate beneficial use of emotion regulation strategies. They focus on cognitive aspects, as well as behavioural aspects. The behavioural part focuses on replacing counterproductive emotional driven behaviours with alternatives. This has a facilitating effect on beneficial use of situation selection, situation modification, and attentional deployment. The cognitive part focuses on substituting irrational negative appraisals for evidence-based appraisals. This has a facilitating effect on beneficial use of cognitive change (Campbell-Sills and Barlow 2006).

\subsection{Developmental Niche Theory (Super \& Harkness, 1986)}

The idea of the developmental niche combines the framework for thinking about human development in cultural context (Super \& Harkness, 1986). It can be used to organize information about children's development and to focus investigations for improving the lives of children and families. Although it is not a theory of development in the formal sense, the developmental niche provides a framework for understanding how cultures guide the process of development. By using this framework, it is to see how the cultural environments of particular children are organized to see how the culture is presented to the child at any particular time. The term niche is borrowed from biological ecology, where it is used to describe the combination of features of the environment a particular animal, or a species of animal, inhabits. Thus a pigeon and a robin might live "in the same place" in the sense of dwelling in the same part of a city park. But exactly where they build their nests and from what materials, $t$ he kind of food they seek in the surrounding environment, their vulnerability to various predators, all these are distinct.

The particular way they fit into and exploit the same general environment is different, and they thus create a distinct niche for themselves. At the centre of the developmental niche, therefore, is a particular child, of a certain sex and age, with certain temperamental and psychological dispositions. By virtue of these and other characteristics, this child will inhabit a different cultural "world" than the worlds inhabited by other members of his family and further, the child's world will also change as the child grows and changes. There are three major aspects of this child's culture that shape his or her life. 
These three components together make up the developmental niche. The first component is the physical and social settings of everyday life. This includes such basic facts of social life as what kind of company the child keeps.In rural Kenya, for example, families are large mothers often have eight or more children-and with the activities of these people based mainly at home, the baby or young child is likely to have several playmates and caretakers who are siblings. The size and shape of the living space is also an important feature of physical and social settings. By contrast, in the southern part of Holland where many people live in a small geographic area, houses are very compact and the living room also serves as the children's playroom. Typically, if there is a baby or toddler in the house, there will be a playpen located in this room, where he or she can play independently with toys while yet in close proximity to other members of the family. Even aspects of life as basic as sleeping and eating schedules are organized by the physical and social settings of daily life.

While Kenyan babies sleep with their mothers and wake to nurse at intervals through the night, for example, Dutch children are put to bed rather early by U.S. standards and learn to stay there until it's time to get up. In contrast, young children in Italy and Spain are often kept up until late at night in order to participate in family and community events. One cannot get very far in studying the physical and social settings of children in different cultures without realizing that many aspects of children's environments are organized by customary practices; and it is for this reason that we identify customs of child care and child rearing as the second component of the developmental niche. The use of older siblings as caretakers in rural Kenya, for example, is customary. There are special terms for these child nurses in the native languages of Kenya, and they are expected to care for their young charges in a special way that is different from mothers 'care.

This fact points to an important aspect of customs-that they are normative for families and communities. Very often, in fact, customs of care are seen by their users as the only reasonable solution to whatever need they address, indeed, the natural way to do things. Customs of care are thus a source of support for parents and other caretakers because they provide ready-made solutions to the myriad of issues that developing children present, from how to protect children from hazards in the environment to how to ensure that they are adequately educated for their future roles in society. But sometimes the function of a custom is less easy to specify because its value is primarily symbolic. To understand these customs of child care and child rearing, one needs to take into account cultural traditions related to spirituality and concepts of the person. Although these abstract dimensions of culture are difficult to describe, the study of customs which represent them can provide insights into the cultural ways of thinking that organize the lives of families and children. It is these cultural ways of thinking and feeling, held by parents and other caretakers that we recognize as the third component of the developmental niche, the psychology of the caretakers.

Parents' cultural belief systems and related emotions underlie the customs of child rearing and validate the organization of physical and social settings of life for children. In cultures where babies and young children customarily sleep close to their parents, for example, parents often feel that to put the child elsewhere-r even worse, to fail to attend to a child who wakes crying in the night-amounts to no less than neglect. First, the settings, customs, and caretaker psychology, as explained above, form the immediate micro-environment of the child: they are the developmental niche. The three doubleheaded arrows represent an important relationship within the niche, that is, that the three components influence each other. A variety of forces, psychological and practical, promote a sense of harmony among the three components. Parents do not easily leave their children in settings which they judge to be dangerous. The customs of child care are generally adapted to the particular physical and social settings, as well as to what are symbolically acceptable to the caretakers. A steady state of complete harmony is rarely achieved, but as the irregular lines separating the components suggest, the points of contact adapting to each other. The larger, single-headed arrows illustrate a second dynamic of the niche, namely that various aspects of the larger human ecology differentially influence the three components of the niche. The customs carry a particular weight of history and area conservative force such that, other things being equal, many parents will, "without thinking," rear their children with many of the same traditions they grew up with. Economic and demographic changes may rapidly affect the settings of daily life for children. They may spend their day with fewer brothers and sisters, in a day care centre, or in an urban environment. The psychology of the caretakers may be directly influenced by shifting ideas at the national or community level about the nature of children and their needs, as well as about what skills they will need for the future. 
In summary, there are many ways that changes in the larger society or physical environment can influence the child, but they do not all operate through the same components of the niche. Finally, the developmental niche formulation recognizes the fact that the child and its environment accommodate each other: Their curves are mutually adjusted. Some views of child development emphasize the way child behaviour is shaped by the environment, that is, the degree to which children must adapt to the requirements of their family and their culture. But it is also true, as more recent research has shown that parents and caretakers alter their demands and their supports in response to the particular temperament and talents of the individual child. In addition, the child is a rapidly changing person, especially in the early years. Language and social skills develop, personal interests emerge, and the child learns to cope with, or avoid, specific features of the niche. The niche, in this sense, also develops in response to the changing child, as well as to the outer influences. of course many features remain constant, or at least present challenges that grow in a way parallel to changes in the child. These are the themes that take on particular strength as the child matures, themes that are most deeply woven into the values, motives, and fears of the emerging adult. The theoretical framework of the developmental niche helps to achieve such an understanding through systematic analysis of the culturally constituted components of the child's environment and their relationships with each other, the wider environment, and the child. In this analysis, it is clear that the cultural environment of the child is powerful not only because it is experienced during the formative years of life, but also because it constitutes an interactive system in which the same cultural messages are conveyed through a variety of modalities. Just as in language where the same idea may be communicated through choice of words, grammatical structure and tone of voice. In cultural environments the child may learn the same ways of thinking and acting through the physical and social settings of daily life, the customs in which he or she participates, and the expressions of parents' ideas that are conveyed in a variety of ways. Over the span of development, these messages become so internalized that they form the core of our understandings of the world and ourselves. It is in this sense that ethos and psyche-culture and individual psychology are fused in the re-creation and transformation of culture within the individual mind

\section{Methodology}

\subsection{Research Design}

This ethnographic study utilized a triangulated research paradigm and the interpretive method. This approach depended on the instrument design model and the data transformation design model. Triangulation refers to the use of more than one approach to the investigation of a research question in order to enhance confidence in the ensuing findings. Since much social research is founded on the use of a single research method and as such may suffer from limitations associated with that method or from the specific application of it, triangulation offers the prospect of enhanced confidence. Triangulation is one of the several rationales for Multi-method Research. The term derives from surveying, where it refers to the use of a series of triangles to map out an area. The idea of triangulation is very much associated with measurement practices in social and behavioral research. Therefore, "By combining multiple observers, theories, methods, and empirical materials, researchers can hope to overcome the weakness or intrinsic biases and the problems that come from singlemethod, single-observer, and single-theory studies. Often the purpose of triangulation in specific contexts is to obtain confirmation of findings through convergence of different perspectives. The point at which the perspectives converge is seen to represent reality." Jakob, Alexander (2001) The qualitative aspects of the study was accentuated because it allowed the researcher to gain insight into the organizational structures and settings, social processes, and more poignantly underscores the importance of personal interviews and narratives on the lived experiences of the respondents as stated by (Strauss and Corbin, 1994). In addition, it also privileges the perceptions of the participants and allows for the development of a rich and in-depth understanding of the community from the viewpoint of its members, by giving precedence to the voices of the participants through their lived experiences. The researcher was better placed to develop a better understanding of individual and group experiences of the research participant.

\subsection{The Study Area}

The study was carried out within selected communities of Bui Division in the North West Region of Cameroon. The North West Region is one of the ten regions of Cameroon. The region is divided into administrative Divisions. Like other regions in Cameroon, the Northwest Region is made up of 
administrative divisions. The province was created in 1972 with five divisions or departments: Bui, Donga-Mantung, Menchum, Mezam, and Momo. Today, it has seven divisions, the additions being Boyo, which was carved out of the Menchum division, and Ngo-Ketunjia or Ngoketunjia, split off from the Mezam division. Each division is further subdivided, with thirty-one total subdivisions in the Northwest Province. The basic unit of local government is the council, and there are thirty-two councils in the region.

The study site was further narrowed to four sub-divisions of Bui Division (Kumbo Central, Nkum, Mbven and Jakiri).

Geographically, Bui Division is situated between latitudes $6^{\circ} 00^{\prime \prime}$ to $6^{\circ} 20^{\prime \prime}$ North of the Equator and longitudes $10^{\circ} 30^{\prime \prime}$ to $10^{\circ} 60^{\prime \prime}$ East of the Greenwich Meridian. It is a huge orographic plateau within the Cameroon Volcanic Line (CVL) with spectacular mountainous landscape like Mount Oku (3.011m above sea level) and the Mbaw-Tikar Plains (about 900m above sea level) (Tume, 2008). The Division has a total surface area of 2,795 2 (Divisional Delegation of Lands, Bui, Kumbo), with Kumbo as its headquarters. It has six Sub Divisions namely: Kumbo Central $\left(630 \mathrm{~km}^{2}\right)$, Jakiri $(675$ $\left.\mathrm{km}^{2}\right),(375.32)$ Nkor-Noni $\left(307.7 \mathrm{~km}^{2}\right)$, Mbiame $\left(575 \mathrm{~km}^{2}\right)$ and Elark-Oku $\left(232 \mathrm{~km}^{2}\right)$. Bui Division is bordered to the North by Donga and Mantung Division, to the North East by Boyo, East by Mentchum, South East by Ngoketunja, and finally in the South West by the Noun Division which is in the Western Region. Bui Division is the second most populated Division in the North West Region of Cameroon with an estimated population of over 400.000 inhabitants and a population density of about 250 persons per $\mathrm{km}^{2}$ (National Institute of Statistics).this population presents a progressive population structure characterized by more youthful population due to increase in birth rates, decrease in infant mortality precipitated by the presence of two efficient hospitals in the area- the Banso Baptist Hospital (BBH), and St. Elizabeth's Catholic General Hospital Shisong, as well as a couple of health centres and dispensaries in rural areas. In relation to trend, the population of Bui Division is experiencing a rapid growth since the 1960s (Divisional Delegation of town Planning, Bui).

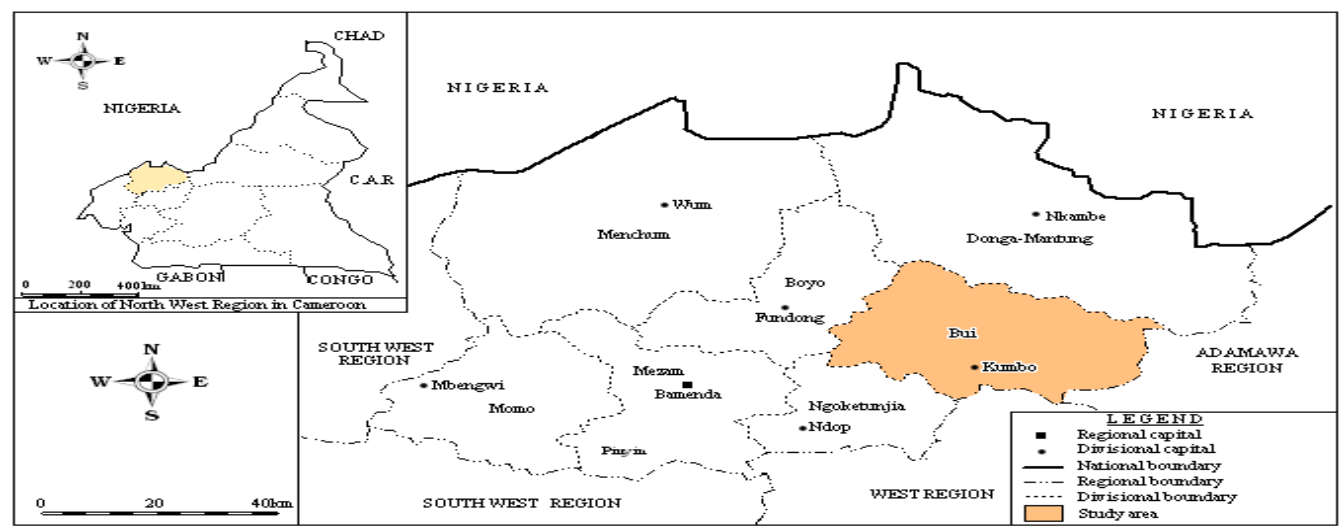

Map1. Location of Bui Division in the North West Region of Cameroon

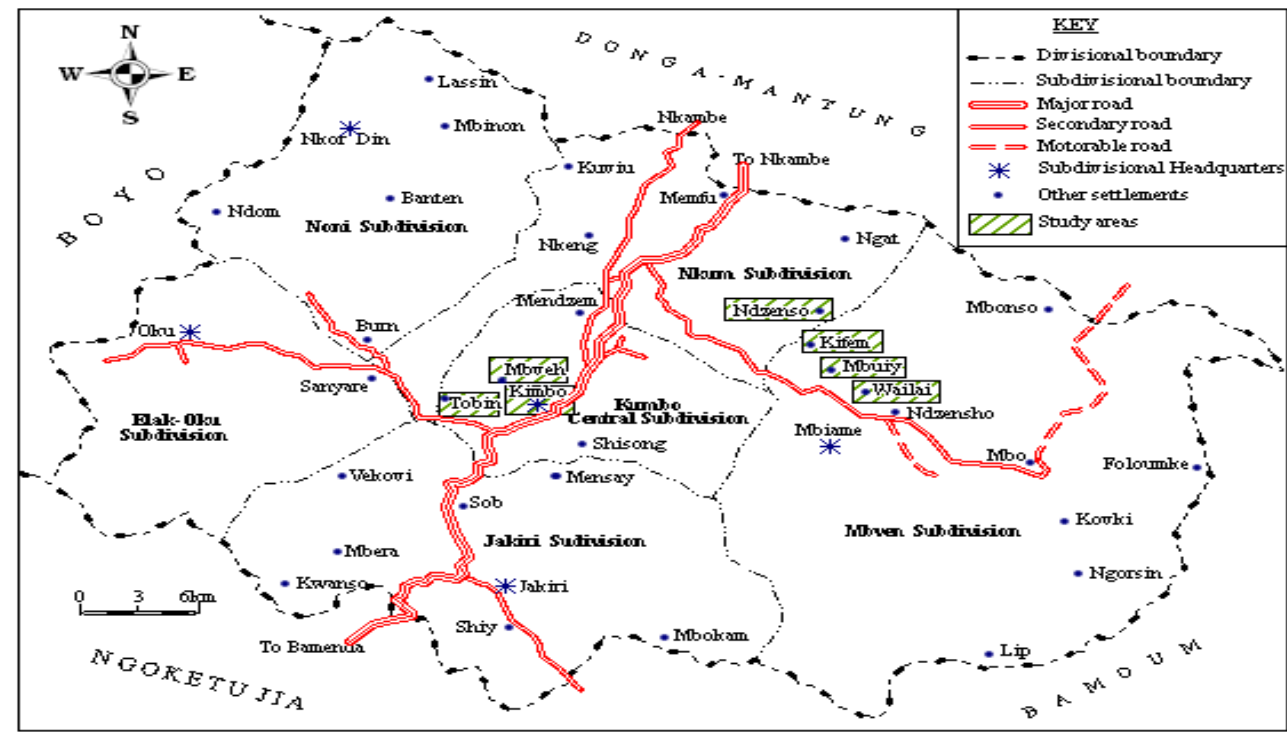

Map2. Location of Study Sites in Bui Division, North West Region of Cameroon 
Dynamics of Indigenous Socialization Strategies and Emotion Regulation Adjustment among Nso Early Adolescents, Norht West Region of Cameroon

\section{Population of the Study}

The scientific method of population identification was adopted in this work and the population is homogenous. This means that all the resource persons had ample knowledge of proverbs as well as indigenous games. The researcher targeted proverbs and indigenous games from the four subdivisions occupied by Nso people. These indigenous modes of socialization are transmitted through the Nso dialect Lamso

Table1.0. Dynamics of Population in Bui Division

\begin{tabular}{|c|c|c|c|c|c|c|c|}
\hline Division & $\begin{array}{c}\text { Sub- } \\
\text { division }\end{array}$ & $\mathbf{( 1 9 7 0 )}$ & $\mathbf{( 1 9 7 6 )}$ & $\begin{array}{c}\mathbf{( 1 9 8 7 )} \\
\text { census }\end{array}$ & $\begin{array}{c}\text { (1998) } \\
\text { projections }\end{array}$ & $\begin{array}{c}\text { (2005) } \\
\text { projections }\end{array}$ & $\begin{array}{c}\text { (2015) } \\
\text { projections }\end{array}$ \\
\hline \multirow{6}{*}{ Bui } & Kumbo** & $/ /$ & $/ /$ & 93884 & 153995 & 210994 & 330862 \\
\cline { 2 - 8 } & Mbven & $/ /$ & $/ /$ & 11952 & 16927 & 21123 & 28984 \\
\cline { 2 - 8 } & Noni & $/ /$ & $/ /$ & 20331 & 23691 & 26112 & 30008 \\
\cline { 2 - 8 } & Jakiri & $/ /$ & $/ /$ & 36315 & 57738 & 77555 & 118216 \\
\cline { 2 - 8 } & Oku & $/ /$ & $/ /$ & 55582 & 78049 & 96870 & 131892 \\
\hline \multicolumn{2}{|c|}{ Total } & $\mathbf{1 1 8 , 0 0 0}$ & $\mathbf{1 5 1 , 8 2 1}$ & $\mathbf{2 1 8 , 0 6 4}$ & $\mathbf{3 3 0 , 4 0 0}$ & $\mathbf{4 3 1 , 6 6 4}$ & $\mathbf{6 3 2 , 4 2 8}$ \\
\hline
\end{tabular}

Kumbo central Sub-Division has been divided into 2 sub-divisions; Kumbo central sub-division and Nkum subdivision. Their population figures shall be considered as Kumbo Central Sub-Division. Source: Njilla, R.M.N. (2010).

Table1.1. Target Population

\begin{tabular}{|c|c|c|c|c|c|}
\hline Sub-division & Men & Women & $\begin{array}{c}\text { Youths } \\
\text { 16-35 years }\end{array}$ & $\begin{array}{c}\text { Children } \\
\text { 0-5 years }\end{array}$ & Total \\
\hline Kumbo Central & 30.030 & 42.956 & 41.222 & 13.711 & $127.919 \mathrm{x}$ \\
\hline Nkum & 49.704 & 57.236 & 29.122 & 9.467 & $145,529 \mathrm{xx}$ \\
\hline Mbven (Mbiame) & 13.093 & 17.289 & 11.650 & 6.652 & $48.684 \mathrm{xxx}$ \\
\hline Jakiri (Dzekwa) & 29.445 & 32.857 & 11.457 & 7.894 & $81,653 \mathrm{xxxx}$ \\
\hline
\end{tabular}

Source: $x$ Cameroon national census results (2010) PVC baseline Kumbo ( 2011)

$X x$ village socio-economic survey, Nkum council development plan, (CDP, 2011)

xxx village socio-economic survey, Mbven council development plan, (CDP, 2011)

xxxx Jakiri council development plan, (CDP, 2012)

Table1.2. Accessible Population

\begin{tabular}{|c|c|c|c|c|c|}
\hline Village & Men & Women & $\begin{array}{c}\text { Youths } \\
\text { 10 to 35 years }\end{array}$ & $\begin{array}{c}\text { Children below } \\
\text { 10 years }\end{array}$ & Total \\
\hline Tobin & 3108 & 3368 & 2500 & 800 & 9776 \\
\hline Mbveh & 2216 & 2643 & 1300 & 1249 & 7408 \\
\hline Kimbo & 1935 & 2379 & 1650 & 200 & 6164 \\
\hline Ndzennso & 400 & 604 & 1233 & 1004 & 3241 \\
\hline Mbuiy & 411 & 600 & 905 & 1002 & 2918 \\
\hline Wailai & 345 & 566 & 890 & 980 & 2781 \\
\hline Kifem & 1555 & 2532 & 1222 & 788 & 6097 \\
\hline Jakiri & 1566 & 2544 & 1805 & 2455 & 8370 \\
\hline
\end{tabular}

Source: council development plans for Bui Division (2012)

The accessible population was the quantity or size or a portion of an entire aggregation of items which were capable of being reached for the research purposes. The eight (8) communities (Kifem, Mbuiy, Wailai, Ndzennso villages and urban communities such as Tobin, Kimbo and Mbveh were purposely selected as the accessible population. The selection was based on the fact that the Nso population is larger and their proverbs and cultural games run through most indigenous groups in the North West Region of Cameroon. Most importantly these villages were selected because cultural values and norms are still held in very high esteem in these traditionally inclined areas.

\section{Sample Population}

From the above accessible population, a sample population of 272 was purposefully selected to meet the objectives of this study. The below table indicates the distribution of sample populatuion 
Table1.3. Distribution of sample

\begin{tabular}{|c|c|c|c|}
\hline Category of pa rticipant & Male & Female & Total \\
\hline Parents( interviewed) & $\mathbf{1 0}$ & $\mathbf{1 0}$ & $\mathbf{2 0}$ \\
\hline Traditional leaders( interviewed) & $\mathbf{1 0}$ & $\mathbf{0}$ & $\mathbf{1 0}$ \\
\hline Teachers( interviewed) & $\mathbf{5}$ & $\mathbf{5}$ & $\mathbf{1 0}$ \\
\hline Early adolescent ( interviewed) & $\mathbf{1 5}$ & $\mathbf{1 5}$ & $\mathbf{3 0}$ \\
\hline Early adolescent ( fill questionnaires) & $\mathbf{8 1}$ & $\mathbf{1 2 1}$ & $\mathbf{2 0 2}$ \\
\hline TOTAL SAMPLE & & $\mathbf{2 7 2}$ \\
\hline
\end{tabular}

\section{Instrumentations for Data Collection}

Five main instruments were used for data collection, this include,

Interview guide for early adolescent's aged rang (9-14).

$>$ Interview guide for parents

$>$ Interview guide for traditional rulers and elders

An emotion regulation adjustment questionnaire (ERAQ)

$>$ Interview was conducted with 10 randomly selected teachers.

\section{Validity and Reliability of Instruments}

\section{Validity of Instruments}

Validity of a study is the ability of its instrument to measure what it is designed to measure (Kumar, 2005). Fraenkel and Wallen (2000) argue that with content validity the following questions are to be taken care of. How appropriate is the content? How comprehensive? Does it logically get at the intended variable? How adequately does the sample of items or questions represent the content to be assessed? Is the format appropriate? In terms of validity, content and construct validity was checked. Content validity focuses on the extent to which the content of instrument corresponded to the content of the theoretical concept. It refers to the degree to which the test actually measures the traits for which it was designed.

\section{Reliability of Instruments}

Ayadoie, (2000), comments that the reliability of a test refers to the degree of consistency and precision (accuracy) with which the test measures what it purports to measure. Reliability therefore, can be referred to as the stability, dependability and consistency of a measuring instrument. The reliability of the instrument used in this study was determined during the pilot study conducted before the main study. Reliability check was paramount as it determined the consistency, stability, predictability, accuracy, dependability or trustworthiness of the scores obtained,-how consistent they were for each individual from one administration of an instrument to another and from one set of items to another (Kumar, 2008; Amin, 2005; Fraenkel \& Wallen, 2000). Reliability was an important indicator which determined a good triangulated research. This also forms part of the scientific integrity of the researcher.

\section{Summary of Data Analysis and Presentation of Findings}

\section{Objective one: Describe how proverbs influence emotion regulation adjustment}

It was observed that in the studied communities, proverbs had a great influence on emotion regulation adjustment with weight of $88.1 \%$ for children who had some experience of proverbs. But it was equally realized that this proportion was also very high among those who had no experience of proverbs $(78.4 \%)$. This difference was not statistically significant $(\chi 2$-test: $\chi 2=0.55 ; \mathrm{df}=1 ; \mathrm{P}=0.458$ ). There was therefore high evidence that in these communities, there exist other factors that contribute to emotion regulation adjustment of children as asserted by this parent who believed that proverbs for instance are just aspect of culture 'Certain cultural aspects cannot be left out' [Male parent] that cannot be neglected. Qualitative data gotten through interviews reveal that other cultural values such as sense of community life, sense of good human relations, sense of the sacredness of life, sense of hospitality, sense of the sacred and of religion, sense of time, sense of respect for authority and the elders, sense of language greatly contributed to the social competences exhibited by respondents.

It is worth noting that some proverbs had played a greater role on the emotion regulation adjustment of early adolescents than others for instance, 
Dynamics of Indigenous Socialization Strategies and Emotion Regulation Adjustment among Nso Early Adolescents, Norht West Region of Cameroon

Proverb 1 and 2 Véshwinéwáa tom àntey wìrdż̀m yò dż̀ réyréy fó kav.....Dż̀ ji wír ve á kéríi wáa tom àghé' nshey. Kiwókilóoyo' kibiy, kibiykiwáayo' Kiwó À lóoyiikinyokejunki e wir, bodż̀ sá mo wù yii a yì̀ kijuy e wò.... Dż̀ é ghan se wìr shiy kinyo ke juykifowìrbì kewir-lìyiin ne wun. (When the hand is rubbing the thigh, the thigh should be rubbing the hand.)The good done to someone should be reciprocated with good.

Proverb 4 Mbè'yò'yiikúyshaakitú À kérfo a ghvemkfòn a yu ygayséwirsébìfoàwuneshaa ànwònlèéjiáwunekérfó a ghvem a ygàyséwirsév. (The shoulder never grows higher than the head) You have to respect and obey your elders because there are older than you.

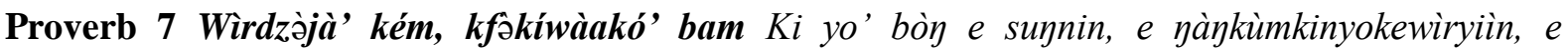
kégha'ákíbènbvòzshíkòóysawun (a person who speaks ill of another while his own wrong doings are worse) It is not good to talk too much about somebody's misdeeds.

Proverb 8 Wìrdż̀ é wìrmoshwà' dż̀วn é ygùr Wiryò’ dż̀shówodż̀wùsùúyjibóyò' dż̀ wun lùyfówìr.....Dż̀ é ghan se wìrkeerin sáfoykarra, a bówùyo’ dż̀ wù keèr shó (A person is to another as the knife is to a handle) There is nobody who cannot benefit from another.

Proverb 10 Wànbaáyò' yiikúybó a shòm. Kíbòyjitàrwàn kin yeèwànwáakerliìwojuy, bì fowànkúyí e nènkù a yiiréyréy moo wun. ..... Dż̀ é ghan se wàn yii réyréy moo kitàrkìnyìy. (the cub of a leopard does not grow before it gets spotted. Also like the father like the son). It is good that a parent should behave well because the child is likely to take after him (One hand cannot tie a bundle) One man cannot accomplish what can be done by many people. $m$ yò dz réyréy fó kav.....Dz ji wír ve á kéríi wáa tom àghé' nshey. sá mo wù yii a yiì kijuy e wò.... Dz é ghan se wìr shiy kinyo ke juykifowìrbì' kewìr-lìyiin ne wunn a yu ygayséwirsébìfoàwuneshaaànwònlèéjiáwunekérfó a ghvem a ygàysjà' kém, kfkíwàakó' bam sshíkòóysawun é wìrmoshwà' dzon é ygùr shówodzwùsùúyjibóyò dz wun lùyfówìr.....Dz é ghan se wìrkeerin sfoykarro, a bówùyo' dz wù keèr shó é ghan se wàn yii réyréy moo kitàrkìnyìy

The above mentioned proverbs indicated a significantly greater influence on emotion regulation adjustment of early adolescents than the other proverbs. Findings also indicate that, emotion regulation of early adolescents did not depend on the socio-economic status of the parents for the two groups (Experience of proverbs: $\chi 2$-test: $\chi 2=1.97 ; \mathrm{df}=5 ; \mathrm{P}=0.852$; No experience of proverbs: $\chi^{2}$-test: $\chi 2=1.63 ; \mathrm{df}=6 ; \mathrm{P}=0.837)$.

Table1.4. Comparing social competence as a function of exposure to proverbs between rural and urban areas

\begin{tabular}{|c|c|c|c|c|c|}
\hline & & & \multicolumn{2}{|c|}{$\operatorname{Pr}^{a}$} & \multirow{2}{*}{ Total } \\
\hline & & & Yes & No & \\
\hline \multirow{6}{*}{ Setting types } & \multirow{3}{*}{ Rural } & Count & 3359 & 925 & 4284 \\
\hline & & $\%$ within a $2 \mathrm{a}$ & $78.4 \%$ & $21.6 \%$ & \\
\hline & & $\%$ of Total & $39.6 \%$ & $10.9 \%$ & $50.5 \%$ \\
\hline & \multirow{3}{*}{ Urban } & Count & 3403 & 797 & 4200 \\
\hline & & $\%$ within a $2 \mathrm{a}$ & $81.0 \%$ & $19.0 \%$ & \\
\hline & & $\%$ of Total & $40.1 \%$ & $9.4 \%$ & $49.5 \%$ \\
\hline \multirow{2}{*}{\multicolumn{2}{|c|}{ Total }} & Count & 6762 & 1722 & 8484 \\
\hline & & $\%$ of Total & $79.7 \%$ & $20.3 \%$ & $100.0 \%$ \\
\hline
\end{tabular}

There was statistically enough evidence that social competence as function of exposure to proverbs did not differ significantly between rural and urban area $(\chi 2$-test: $\chi 2=0.21 ; \mathrm{df}=1 ; \mathrm{P}=0.650)$.

Modelling social competence

Table: 1.5 Logistic Regression Model depicting the predictive power of proverbs/indicators of social competence on emotion regulation adjustment of early adolescents

\begin{tabular}{|c|c|c|c|c|c|c|}
\hline \multirow{5}{*}{ Predictive components } & \multicolumn{2}{|c|}{ Male (N=121) } & \multicolumn{2}{c|}{ Female (N=81) } & \multicolumn{2}{c|}{ All (N=202) } \\
\cline { 2 - 7 } & $\begin{array}{c}\text { Omnibus Tests of } \\
\text { Model } \\
\text { Coefficients } \\
\text { Chi-square level } \\
\text { of significance) }\end{array}$ & $\begin{array}{c}\text { Cox \& } \\
\text { Snell R } \\
\text { Square }\end{array}$ & $\begin{array}{c}\text { Omnibus Tests of } \\
\text { Model } \\
\text { Coefficients } \\
\text { (Chi-square level } \\
\text { of significance) }\end{array}$ & $\begin{array}{c}\text { Cox \& } \\
\text { Snell R } \\
\text { Square }\end{array}$ & $\begin{array}{c}\text { Model } \\
\text { Coefficients (Chi- } \\
\text { square level of } \\
\text { significance) }\end{array}$ & $\begin{array}{c}\text { Cox \& } \\
\text { Snell R } \\
\text { Square }\end{array}$ \\
\hline Sharing & $\mathrm{P}=0.077$ & $3.3 \%$ & $\mathrm{P}=0.062$ & $6.7 \%$ & $\mathrm{P}=0.246$ & $1.1 \%$ \\
\hline Humility & $\mathrm{P}=0.488$ & $1.2 \%$ & $\mathrm{P}=0.248$ & $5.0 \%$ & $\mathrm{P}=0.065$ & $4.4 \%$ \\
\hline Group compliance & $\mathrm{P}<0.001$ & $11.3 \%$ & $\mathrm{P}=0.075$ & $8.2 \%$ & $\mathrm{P}=0.986$ & $0.1 \%$ \\
\hline Respect for elders & $\mathrm{P}<0.001$ & $13.7 \%$ & $\mathrm{P}<0.001$ & $22.1 \%$ & $\mathrm{P}=0.031$ & $7.1 \%$ \\
\hline
\end{tabular}


Therese Mungah Shalo Tchombe \& Tani Emmanuel Lukong

\begin{tabular}{|c|c|c|c|c|c|c|}
\hline \hline Sense of appreciation & $\mathrm{P}<0.001$ & 11.4 & $\mathrm{P}<0.001$ & $33.4 \%$ & $\mathrm{P}=0.001$ & $12.8 \%$ \\
\hline Respect for all & $\mathrm{P}=0.024$ & $4.6 \%$ & $\mathrm{P}<0.001$ & $22.0 \%$ & $\mathrm{P}=0.001$ & $12.6 \%$ \\
\hline Self examination & $\mathrm{P}=0.079$ & $3.3 \%$ & $\mathrm{P}=0.041$ & $9.7 \%$ & $\mathrm{P}=0.001$ & $12.9 \%$ \\
\hline Sense of collectivity & $\mathrm{P}<0.001$ & $10.5 \%$ & $\mathrm{P}=0.074$ & $8.2 \%$ & $\mathrm{P}=0.222$ & $3.6 \%$ \\
\hline Self-control & $\mathrm{P}=0.001$ & $7.4 \%$ & $\mathrm{P}<0.001$ & $22.5 \%$ & $\mathrm{P}=0.026$ & $7.4 \%$ \\
\hline Modelling & $\mathrm{P}<0.001$ & $8.9 \%$ & $\mathrm{P}=0.004$ & $15.0 \%$ & $\mathrm{P}=0.126$ & $4.6 \%$ \\
\hline Sense of unity & $\mathrm{P}<0.001$ & $9.3 \%$ & $\mathrm{P}=0.165$ & $6.1 \%$ & $\mathrm{P}=0.003$ & $11.1 \%$ \\
\hline Avoid selfishness & $\mathrm{P}<0.001$ & $11.3 \%$ & $\mathrm{P}=0.228$ & $5.2 \%$ & $\mathrm{P}=0.011$ & $13.6 \%$ \\
\hline Tolerance & $\mathrm{P}<0.001$ & $11.9 \%$ & $\mathrm{P}=0.144$ & $6.5 \%$ & $\mathrm{P}<0.001$ & $18.6 \%$ \\
\hline Care for elders & $\mathrm{P}<0.001$ & $9.6 \%$ & $\mathrm{P}=0.096$ & $7.5 \%$ & $\mathrm{P}<0.001$ & $18.9 \%$ \\
\hline IVM & $\mathrm{P}<0.001$ & $74.9 \%$ & $\mathrm{P}<0.001$ & $74.8 \%$ & $\mathrm{P}<0.001$ & $75.0 \%$ \\
\hline
\end{tabular}

Source: Generated from Questionnaire Analysis by Author (May, 2014)

Objective 2: Examine how indigenous games influence emotion regulation adjustment

Table1.6. Distribution of problems solving ability among early adolescent

\begin{tabular}{|c|c|c|c|c|}
\hline \multirow{2}{*}{$\begin{array}{l}\text { Problem solving } \\
\text { ability indicators }\end{array}$} & \multirow[b]{2}{*}{ Indices } & \multicolumn{2}{|c|}{ Perceived problem solving ability } & \multirow[b]{2}{*}{$\chi 2$-test } \\
\hline & & $\begin{array}{c}\text { Not exposed } \\
(\mathrm{N}=102)\end{array}$ & $\begin{array}{l}\text { Exposed } \\
(\mathrm{N}=100) \\
\end{array}$ & \\
\hline \multirow{3}{*}{ Compromise } & $\begin{array}{l}\text { I accept the will of others } \\
\text { because I want to continue to } \\
\text { play with them }\end{array}$ & $18(17.6 \%)$ & $74(74.0 \%)$ & $\begin{array}{l}\chi 2=64.66 \\
P<0.001\end{array}$ \\
\hline & $\begin{array}{l}\text { I continue to play because I am } \\
\text { afraid of problems }\end{array}$ & $6(5.9 \%)$ & $68(68.0 \%)$ & $\begin{array}{l}\chi 2=83.93 \\
\mathrm{P}<0.001\end{array}$ \\
\hline & $\begin{array}{l}\text { I always share part of the blame } \\
\text { for the conflict }\end{array}$ & $6(5.9 \%)$ & $72(72.0 \%)$ & $\begin{array}{l}\chi 2=93.13 \\
\mathrm{P}<0.001\end{array}$ \\
\hline \multirow{3}{*}{ Avoidance } & $\begin{array}{l}\text { I always chose to become a } \\
\text { spectator to avoid problems }\end{array}$ & $89(87.3 \%)$ & $69(69.0 \%)$ & $\begin{array}{l}\chi 2=9.88 \\
P=0.002\end{array}$ \\
\hline & $\begin{array}{l}\text { I allow the game and go home } \\
\text { when there is conflict }\end{array}$ & $33(32.4 \%)$ & $60(60.0 \%)$ & $\begin{array}{l}\chi 2=15.54 \\
\mathrm{P}<0.001\end{array}$ \\
\hline & $\begin{array}{l}\text { I decide to play with others or } \\
\text { alone when there is conflict }\end{array}$ & $10(9.8 \%)$ & $68(68.0 \%)$ & $\begin{array}{l}\chi 2=72.15 \\
P<0.001\end{array}$ \\
\hline \multirow{3}{*}{ Dialogue } & $\begin{array}{l}\text { I am always ready to talk with } \\
\text { my friends despite the conflict }\end{array}$ & $4(3.9 \%)$ & $71(71.0 \%)$ & $\begin{array}{l}\chi 2=97.33 \\
\mathrm{P}<0.001\end{array}$ \\
\hline & $\begin{array}{l}\text { I always ask and answer each } \\
\text { other's question until we have } \\
\text { the truth or response }\end{array}$ & $4(3.9 \%)$ & $66(66.0 \%)$ & $\begin{array}{l}\chi 2=85.93 \\
\mathrm{P}<0.001\end{array}$ \\
\hline & $\begin{array}{l}\text { I listen and take the opinion of } \\
\text { the elderly and experienced peer }\end{array}$ & $3(2.9 \%)$ & $67(67.0 \%)$ & $\begin{array}{l}\chi 2=91.5 \\
P<0.001\end{array}$ \\
\hline \multirow{3}{*}{ Forgiveness } & $\begin{array}{l}\text { I am always ready to ask for } \\
\text { forgiveness when I am wrong }\end{array}$ & $3(2.9 \%)$ & $76(76.0 \%)$ & $\begin{array}{c}\chi 2=113.18 \\
P<0.001\end{array}$ \\
\hline & $\begin{array}{l}\text { I prefer to forgive others when } \\
\text { they ask for forgiveness }\end{array}$ & $2(2.0 \%)$ & $75(75.0 \%)$ & $\begin{array}{c}\chi 2=114.20 \\
\mathrm{P}<0.001\end{array}$ \\
\hline & $\begin{array}{l}\text { I am always ready to forgive } \\
\text { others even when they don't ask } \\
\text { for forgiveness }\end{array}$ & $2(2.0 \%)$ & $68(68.0 \%)$ & $\begin{array}{c}\chi 2=97.25 \\
P<0.001\end{array}$ \\
\hline \multirow{3}{*}{$\begin{array}{l}\text { Solicit for elderly } \\
\text { intervention }\end{array}$} & $\begin{array}{l}\text { I prefer to ask an elder to } \\
\text { separate a fight }\end{array}$ & $2(2.0 \%)$ & $76(76.0 \%)$ & $\begin{array}{c}\chi 2=116.78 \\
\mathrm{P}<0.001\end{array}$ \\
\hline & $\begin{array}{l}\text { I prefer ask the elder to decide } \\
\text { who is wrong and who is right }\end{array}$ & $2(2.0 \%)$ & $70(70.0 \%)$ & $\begin{array}{c}\chi 2=101.91 \\
\mathrm{P}<0.001\end{array}$ \\
\hline & $\begin{array}{l}\text { I always prefer to ask the elder } \\
\text { to punish the aggressor }\end{array}$ & $2(2.0 \%)$ & $70(70.0 \%)$ & $\begin{array}{c}\chi 2=101.91 \\
\mathrm{P}=0.001\end{array}$ \\
\hline & MRS & $186(12.2 \%)$ & $1050(70.0 \%)$ & $\begin{array}{c}\chi 2=160.190 \\
P<0.001\end{array}$ \\
\hline
\end{tabular}

Source: Generated from Questionnaire Analysis by Author (May, 2014)

Findings reveal that, indigenous games highly contribute to problem solving ability of early adolescence as $70.0 \%$ of them who had experience of indigenous games portrait such ability against a significantly lower rate $12.2 \%$ for those not exposed $(\chi 2$-test: $\chi 2=160.190 ; \mathrm{df}=1 ; \mathrm{P}<0.001)$.Problem solving ability of early adolescents unlike for the proverb cohort was significantly influenced by the occupation of the parents $(\chi 2$-test: $\chi 2=11.02 ; \mathrm{df}=4 ; \mathrm{P}=0.026)$ : There was statistically enough evidence 
that respondents whose parents exercised unskilled or semi-skilled work had more problem solving ability even when not exposed to game while exposure to game improve problem solving ability of respondents whose parents exerted skilled work. Justifiably, the study indicates that indigenous games greatly contribute in helping early adolescents regulate their emotions for effective cultural adaptation.

\section{Modelling problem solving ability}

Table1.7. Logistic Regression Model depicting the predictive power of indigenous games /indicators of problem solving ability on ERA

\begin{tabular}{|c|c|c|c|c|c|c|}
\hline \multirow{2}{*}{$\begin{array}{c}\text { Predictive } \\
\text { components }\end{array}$} & $\begin{array}{c}\text { Omnibus Tests } \\
\text { of Model } \\
\text { Coefficients } \\
\text { (Chi-square } \\
\text { level of } \\
\text { significance) }\end{array}$ & $\begin{array}{c}\text { Cox \& } \\
\text { Snell R } \\
\text { Square }\end{array}$ & $\begin{array}{c}\text { Omnibus Tests of } \\
\text { Model } \\
\text { Coefficients } \\
\text { (Chi-square level } \\
\text { of significance) }\end{array}$ & $\begin{array}{c}\text { Fox \& } \\
\text { Snell R } \\
\text { Square }\end{array}$ & $\begin{array}{c}\text { Omnibus Tests } \\
\text { of Model } \\
\text { Coefficients } \\
\text { (Chi-square } \\
\text { level of } \\
\text { significance) }\end{array}$ & $\begin{array}{c}\text { Cox \& } \\
\text { Snell R } \\
\text { Square }\end{array}$ \\
\hline Compromise & $\mathrm{P}<0.001$ & $49.7 \%$ & $\mathrm{P}<0.001$ & $45.8 \%$ & $\mathrm{P}<0.001$ & $52.9 \%$ \\
\hline Avoidance & $\mathrm{P}<0.001$ & $42.1 \%$ & $\mathrm{P}<0.001$ & $46.1 \%$ & $\mathrm{P}<0.001$ & $42.2 \%$ \\
\hline Dialogue & $\mathrm{P}<0.001$ & $60.7 \%$ & $\mathrm{P}<0.001$ & $55.7 \%$ & $\mathrm{P}<0.001$ & $65.0 \%$ \\
\hline Forgiveness & $\mathrm{P}<0.001$ & $63.4 \%$ & $\mathrm{P}<0.001$ & $64.2 \%$ & $\mathrm{P}<0.001$ & $63.3 \%$ \\
\hline $\begin{array}{c}\text { Solicit for elderly } \\
\text { intervention }\end{array}$ & $\mathrm{P}<0.001$ & $58.2 \%$ & $\mathrm{P}<0.001$ & $55.5 \%$ & $\mathrm{P}<0.001$ & $59.8 \%$ \\
\hline IVM & $\mathrm{P}<0.001$ & $74.7 \%$ & $\mathrm{P}<0.001$ & $73.9 \%$ & $\mathrm{P}<0.001$ & $75.0 \%$ \\
\hline
\end{tabular}

Source: Generated from Questionnaire Analysis by Author (May, 2014)

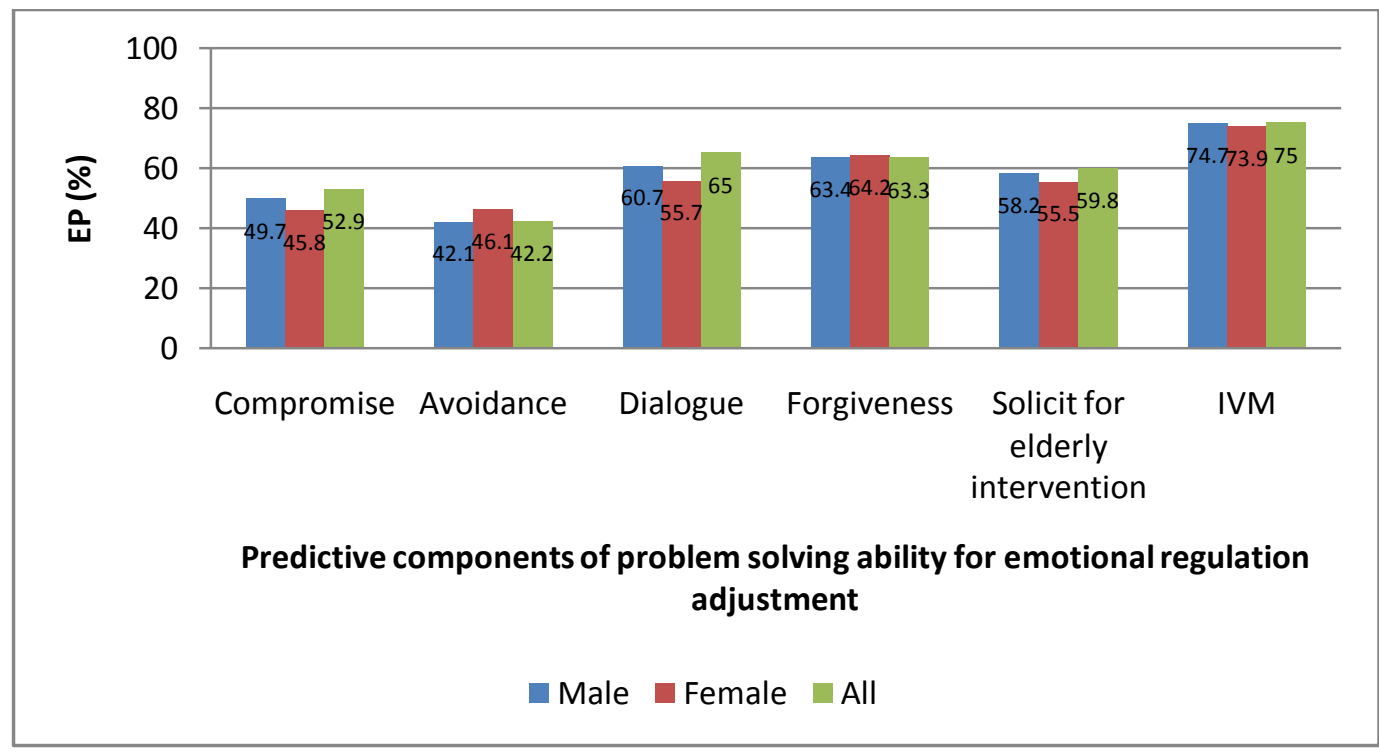

Figure1.3. Logistic Regression Model depicting the predictive power of indigenous games /indicators of problem solving ability on ERA

Unlike proverbs, all the components of problem solving significantly explained emotion regulation adjustment of early adolescents and their EPs (Explanatory power) were generally good, almost 50\% for all and the Integrated Value Mapping (IVM) had a very high explanatory power of $75.0 \%$ with only $15 \%$ of variability loss. This missing variability though small in a modelling context, indicates that there are other factors besides those considered in this study that contribute to emotion regulation adjustment of early adolescents. Individual games impacted emotion regulation adjustment highly unlike proverbs whereby only the aggregated effects of several indicators could bring a reasonable contribution to emotion regulation adjustment. That is, a single indigenous game can influence diverse indicators of emotion regulation adjustment unlike proverbs. Comparing between male and female, it was observed that the EP was higher for females for components, forgiveness, and avoidance and was higher for males in components such as compromise, dialogue and solicit for elderly intervention. It was realized that children in those communities where those games are practiced play all the games. 
The only difference could be at the level of frequency of play but this was not captured by the study and only the duration of exposure was captured but they apply the same duration to all the games. Consequently, the variability for exposure and duration is null.

\section{Objective Three: Determine If There Is Gender Differences In Emotion Regulation Patterns Among Early Adolescents Exposed To Indigenous Games Or Proverbs}

findings reveal that social competence in relation to experience or non experience of proverbs was not dependent of $\operatorname{sex}(\chi 2$-test: $\chi 2=0.01 ; \mathrm{df}=1 ; \mathrm{P}=0.930)$. As for the group with experience of proverbs, the weight of those who portrait social competence was almost equally shared among the male and the female with weight of $81.2 \%$ and $80.9 \%$ respectively. As for those with no experience of proverbs, $79.0 \%$ of the males portrait social competence against a relatively lower rate for the female $(78.0 \%)$ but this difference was not statistically significant (experience of proverbs: $\chi^{2}$-test: $\chi^{2}=1.249$; $\mathrm{df}=1$; $\mathrm{P}=0.264$ ). In overall (including those exposed and not exposed) $80.1 \%$ of the male against $79.5 \%$ of the female had high social competence. This simply means that, the high rate of social competence skills exhibited by both boys and girls exposed to indigenous proverbs could not be linked directly or associated to their knowledge and understanding of proverbs. This is so because the group which was made up of early adolescents not exposed to proverbs still recorded a very high score on social competence skills. However, qualitative data from interviews indicate that other cultural values such as Sense of hospitality; Sense of the sacred and of religion; Sense of time; Sense of respect for authority and the elders; and Sense of language and proverbs contributed to the high acquisition of social competence skills by both respondents.

Table1.8. Distribution of problem solving ability by sex

\begin{tabular}{|c|c|c|c|c|c|c|}
\hline \multirow{3}{*}{$\begin{array}{l}\text { Problem solving ability } \\
\text { indicators }\end{array}$} & \multicolumn{5}{|c|}{ Exposure } & \multirow{3}{*}{$\chi^{2 \text {-test }}$} \\
\hline & \multicolumn{2}{|c|}{ Not exposed } & \multirow[b]{2}{*}{$\chi 2$-test } & \multicolumn{2}{|c|}{ Exposed } & \\
\hline & $\begin{array}{c}\text { Male } \\
(\mathrm{N}=42)\end{array}$ & $\begin{array}{l}\text { Female } \\
(\mathrm{N}=60)\end{array}$ & & Male & Female & \\
\hline $\begin{array}{l}\text { I accept the will of others } \\
\text { because I want to continue } \\
\text { to play with them }\end{array}$ & $8(19.0 \%)$ & $10(16,7 \%)$ & $\begin{array}{l}\chi 2=0.096 \\
\mathrm{P}=0.756\end{array}$ & $27(69.2 \%)$ & $47(77.0 \%)$ & $\begin{array}{c}\chi 2=0.756 \\
\mathrm{p}=0.385\end{array}$ \\
\hline $\begin{array}{c}\text { I continue to play because I } \\
\text { am afraid of problems }\end{array}$ & $2(4.8 \%)$ & $4(6.7 \%)$ & $\begin{array}{c}\chi 2=0.162 \\
\mathrm{P}=0.687\end{array}$ & $23(59.0 \%)$ & $45(73.8 \%)$ & $\begin{array}{c}\chi 2=2.393 \\
p=0.122\end{array}$ \\
\hline $\begin{array}{l}\text { I always share part of the } \\
\text { blame for the conflict }\end{array}$ & $2(4.8 \%)$ & $4(6.7 \%)$ & $\begin{array}{l}\chi 2=0.162 \\
\mathrm{P}=0.687\end{array}$ & $28(71.8 \%)$ & $44(72.1 \%)$ & $\begin{array}{c}\chi 2=0.001 \\
p=0.971\end{array}$ \\
\hline $\begin{array}{l}\text { I always chose to become a } \\
\text { spectator to avoid problems }\end{array}$ & $37(88.1 \%)$ & $52(86.7 \%)$ & $\begin{array}{c}\chi 2=0.045 \\
\mathrm{P}=0.831\end{array}$ & $26(66.7 \%)$ & $43(70.0 \%)$ & $\begin{array}{c}\chi 2=0.163 \\
p=0.687\end{array}$ \\
\hline $\begin{array}{l}\text { I allow the game and go } \\
\text { home when there is conflict }\end{array}$ & $0(0.0 \%)$ & $33(55.0 \%)$ & $\begin{array}{c}\chi 2=34.148 \\
P<0.001\end{array}$ & $22(56.4 \%)$ & $38(62.3 \%)$ & $\begin{array}{c}\chi 2=0.343 \\
\mathrm{p}=0.558\end{array}$ \\
\hline $\begin{array}{l}\text { I decide to play with others } \\
\text { or alone when there is } \\
\text { conflict }\end{array}$ & $0(0.0 \%)$ & $10(16.7 \%)$ & $\begin{array}{l}\chi 2=7.761 \\
\mathrm{P}=0.005\end{array}$ & $27(69.2 \%)$ & $41(67.2 \%)$ & $\begin{array}{c}\chi 2=0.045 \\
\mathrm{p}=0.833\end{array}$ \\
\hline $\begin{array}{c}\text { I am always ready to talk } \\
\text { with my friends despite the } \\
\text { conflict }\end{array}$ & $0(0.0 \%)$ & $4(6.7 \%)$ & $\begin{array}{l}\chi 2=2.914 \\
\mathrm{P}=0.088\end{array}$ & $28(71.8 \%)$ & $43(70.5 \%)$ & $\begin{array}{l}\chi 2=020 \\
p=0.889\end{array}$ \\
\hline $\begin{array}{c}\text { I always ask and answer } \\
\text { each other's question until } \\
\text { we have the truth or } \\
\text { response }\end{array}$ & $0(0.0 \%)$ & $4(6.7 \%)$ & $\begin{array}{l}\chi 2=2.914 \\
\mathrm{P}=0.088\end{array}$ & $27(69.2 \%)$ & $39(63.9 \%)$ & $\begin{array}{c}\chi 2=0.297 \\
\mathrm{p}=0.586\end{array}$ \\
\hline $\begin{array}{c}\text { I listen and take the opinion } \\
\text { of the elderly and } \\
\text { experienced peer }\end{array}$ & $0(0.0 \%)$ & $3(5.0 \%)$ & $\begin{array}{c}\chi 2=2.164 \\
\mathrm{P}=0.141\end{array}$ & $26(66.7 \%)$ & $41(67.2 \%)$ & $\begin{array}{c}\chi 2=0.003 \\
\mathrm{p}=0.955\end{array}$ \\
\hline $\begin{array}{c}\text { I am always ready to ask for } \\
\text { forgiveness when I am } \\
\text { wrong }\end{array}$ & $0(0.0 \%)$ & $3(5.0 \%)$ & $\begin{array}{l}\chi 2=2.164 \\
\mathrm{P}=0.141\end{array}$ & $29(74.4 \%)$ & $47(77.0 \%)$ & $\begin{array}{c}\chi 2=0.094 \\
p=0.759\end{array}$ \\
\hline $\begin{array}{c}\text { I prefer to forgive others } \\
\text { when they ask for } \\
\text { forgiveness }\end{array}$ & $0(0.0 \%)$ & $2(3.3 \%)$ & $\begin{array}{c}\chi 2=1.428 \\
\mathrm{P}=0.232\end{array}$ & $28(71.8 \%)$ & $47(77.0 \%)$ & $\begin{array}{c}\chi 2=0.350 \\
p=0.554\end{array}$ \\
\hline $\begin{array}{l}\text { I am always ready to forgive } \\
\text { others even when they don't } \\
\text { ask for forgiveness }\end{array}$ & $0(0.0 \%)$ & $2(3.3 \%)$ & $\begin{array}{c}\chi 2=1.428 \\
\mathrm{P}=0.232\end{array}$ & $25(64.1 \%)$ & $43(70.5 \%)$ & $\begin{array}{c}\chi 2=0.446 \\
p=0.504\end{array}$ \\
\hline
\end{tabular}


Dynamics of Indigenous Socialization Strategies and Emotion Regulation Adjustment among Nso Early Adolescents, Norht West Region of Cameroon

\begin{tabular}{|c|c|c|c|c|c|c|}
\hline $\begin{array}{c}\text { I prefer to ask an elder to } \\
\text { separate a fight }\end{array}$ & $0(0.0 \%)$ & $2(3.3 \%)$ & $\begin{array}{c}\chi 2=1.428 \\
\mathrm{P}=0.232\end{array}$ & $28(71.8 \%)$ & $48(78.7 \%)$ & $\begin{array}{c}\chi 2=0.620 \\
\mathrm{p}=0.431\end{array}$ \\
\hline $\begin{array}{c}\text { I prefer ask the elder to } \\
\text { decide who is wrong and } \\
\text { who is right }\end{array}$ & $0(0.0 \%)$ & $2(3.3 \%)$ & $\begin{array}{c}\chi 2=1.428 \\
\mathrm{P}=0.232\end{array}$ & $24(61.5 \%)$ & $46(75.4 \%)$ & $\begin{array}{c}\chi 2=2.180 \\
\mathrm{p}=0.140\end{array}$ \\
\hline $\begin{array}{c}\text { I always prefer to ask the } \\
\text { elder to punish the aggressor }\end{array}$ & $0(0.0 \%)$ & $2(3.3 \%)$ & $\begin{array}{c}\chi 2=1.428 \\
\mathrm{P}=0.232\end{array}$ & $26(66.7 \%)$ & $44(72.1 \%)$ & $\begin{array}{c}\chi 2=0.338 \\
\mathrm{p}=0.561\end{array}$ \\
\hline $\begin{array}{c}\text { MRS (N } \mathrm{N}_{\text {responses }} \text { ) Male=630 } \\
\text { Female= } 900\end{array}$ & $49(7.8 \%)$ & $127(14.1 \%)$ & $\begin{array}{c}\chi 2=14.60 \\
\mathrm{P}=0.001\end{array}$ & $394(62.5 \%)$ & $656(72.9 \%)$ & $\begin{array}{c}\chi 2=18.44 \\
\mathrm{p}=0.002\end{array}$ \\
\hline
\end{tabular}

Relationship between problem solving ability and social competence

Table1.9. Relationship between problem solving skill and social competence

\begin{tabular}{|c|c|c|c|c|}
\hline & & & $\begin{array}{l}\text { Score problem } \\
\text { solving ability }\end{array}$ & $\begin{array}{l}\text { Score social } \\
\text { competence }\end{array}$ \\
\hline \multirow{6}{*}{ Spearman's rho } & \multirow{3}{*}{$\begin{array}{l}\text { Score problem solving } \\
\text { ability }\end{array}$} & $\begin{array}{l}\text { Correlation } \\
\text { Coefficient }\end{array}$ & 1.000 & $.155^{*}$ \\
\hline & & Sig. (2-tailed) & . & .027 \\
\hline & & $\mathrm{N}$ & 202 & 202 \\
\hline & \multirow{3}{*}{ Score social competence } & $\begin{array}{l}\text { Correlation } \\
\text { Coefficient }\end{array}$ & $.155^{*}$ & 1.000 \\
\hline & & Sig. (2-tailed) & .027 & . \\
\hline & & $\mathrm{N}$ & 202 & 202 \\
\hline
\end{tabular}

Results reveal that there is a significant though weak positive correlation between problem solving ability and social competence, in the other sense, the more the social competence, the more the ability to solve problems and vice versa (Spearman's rho: $\mathrm{R}=0.155 ; \mathrm{P}=0.027 ; \mathrm{N}=202$ ).

\section{DisCUSSIONS, EDUCATIONAL IMPLICATIONS AND CONCLUDING REMARKS}

The centrality of this study posits that, indigenous strategies of socialization are central contextual tools to effectively demonstrate acceptable emotional behaviours for quality cultural adaptation. Early adolescent's emotional competence was related in mostly expected ways with indigenous proverbs and games as socialization strategies. The results have important implications for educational policy and implementation and the theoretical role of emotion regulation through social competence, problem solving skills and emotional competence during early adolescents. This section present discussion based on the following objectives;

1) Objective One; indigenous proverbs influence emotion regulation adjustment.

2) Objective Two; indigenous games influence emotion regulation adjustment.

3) Objective Three; gender differences of emotion regulation adjustment patterns.

\section{Objective One; How Indigenous Proverbs Influence Emotion Regulation Adjustment.}

Quantitative results from objective one indicated that, proverbs had a statistically significant influence on emotion regulation adjustment of early adolescents who had experience of proverbs. Indigenous proverbs also had a moderately significant influence on the emotion regulation adjustment of early adolescence that had no experience of proverbs. High predictive indicators of indigenous proverbs which significantly influenced emotion regulation adjustment of early adolescent included, Sense of humility, group compliance, respect for all, self-awareness, self control, collective spirit, tolerance, sense of unity and role modelling. Moderately significant predictive indicators of proverbs on early adolescence emotion regulation adjustment included care for elders; avoid selfishness, sense of appreciation, sensitivity to others' needs, and emotional awareness. There was no statistical gender difference amongst indicators to measure indigenous proverbs and emotion regulation adjustment. See figure 5.0: (logistic regression framework below indicating the predictive power of proverbs on emotion regulation adjustment). However, qualitative results greatly supported the exceeding mentioned quantitative realities as discussed below. Qualitatively, other factors greatly contributed to the emotion regulation adjustment of early adolescence as asserted by most parents who believed that proverbs for instance are just aspect of culture 'Certain cultural aspects cannot be left out' [male 
parent] and also cannot be neglected. Qualitative data gotten through interviews with parents, traditional rulers, teachers and early adolescent themselves revealed that other cultural values such as, sense of community life, sense of good human relations, sense of the sacredness of life, Sense of hospitality, sense of the sacred and of religion, sense of time, sense of respect for elders, sense of language and proverbs greatly contributed to the social competences exhibited by respondents as discussed underneath.

Findings make obvious that, in the traditional Nso society, great importance is attached to character training. The child is expected to be sociable, honest, courageous, humble, persevering and of good report at all times. He is educated in the codes of conduct, patterns of moral behaviour, and laws of the society, (by parents, siblings, grandparents, relations and neighbours). Proverbs, legends and folk stories of morality and good manners are employed to drive home some practical truths. Teachers should employ some of the mediums used in traditional education such as folk stories with good moral implications. The collaborative interactions observed in this study are shaped around the concepts of children actively participating in their development as well as the impact of children's peer interactions on their development. Children constantly communicated their knowledge, skills, and ideas both verbally and none verbally with each other throughout their interactions and coordinated their participation to create a collaborative experience. It was in these instances that the children assumed the roles of teacher and learner. As children displayed their skills, verbally expressed their knowledge, and shared their ideas in a directive and exploratory tone, they act as a teacher communicating with a learner in a reciprocal manner. As their peers received the information through listening or observing, they modelled the behaviour, contemplate in relation to their own thinking, or collaborated towards a shared goal.

It is evident from the above discussion that there is a strong correlation between indigenous modes of socialization and the emotion regulation ability of Nso early adolescence. The below flow chart titled figure 5.0: logistic regression framework indicates the predictive power of proverbs on emotion regulation adjustment as revealed by the present study. As emotion regulation adjustment is acquisitive and of social origin, parents and children thus expose their emotions in an expressive way to one another, either consciously or unconsciously in their interactions. It seems that further to individual differences of boy and girl, the expectations of society and people around, especially parents, are different in terms of children's emotional competence. Culturally, girls are mostly expected to be more expressive of feelings, whereas abstaining from feelings expression in boys is strengthened as a manly model. Rather, the research showed that emotion regulation adjustment is meaningful not associated with gender differences as there were no gender significant differences in regulating emotions through indigenous proverbs as indicated by the above flow chart. . Therefore, cultural adaptation through the regulation of emotions is justifiably based on indigenous proverbs as a strategy of socialisation.

Through the cultural processes of guided participation, direct instruction, role modelling or imitation, observation and questioning, emotional competencies are learned from indigenous proverbs. Among indicators to measure emotion regulation adjustment through proverbs, majority had great significant influence on emotion regulation adjustment as indicated by (predictive indicators of social competence). Other indicators had a moderately significant influence on emotion regulation adjustment as indicated by (predictive indicators of social competence). Findings emerging from objective one are consistent with the works of Yatta (2007). Yatta (2007), revealed the relationship between proverbs (oral tradition) and children's ability to develop social competence skills, this study by Yatta (2007) amongst the Mende people of Sierra Leone. Yatta observed that as there were no written records of the ancient past of the Mende people, all that has been preserved of their knowledge, proverbs myths, philosophies, liturgies, songs, and sayings was handed down by word of mouth from generation to generation. These oral media preserved, more or less accurately, the history of the people, their general outlook on life, and their conduct and socio-cultural values, which were used in Mende rural communities as forms of indigenous ways of socialization. This played an important role in the education of the young. For example, adults would gather youngsters around a fire at night and tell them great stories and legends about the past that helped the youngsters to grasp the prevailing ethical standards of their community.

Stories that personified animal characters were often told, and these stories, while explaining the peculiar trait of each animal, also transmitted the virtues valued by the society. For example, stories 
about kasiloi (the spider), always taught youngsters about the unwanted consequences of traits such as greed, egotism, disobedience, or cunnings and promotes culturally relevant social competence such as sharing (sensitive to other's needs), humility, group compliance, respect for elders, sense of appreciation, self examination, sense of collectivity, self-control and hard work. In addition to stories, proverbs were used in Mende indigenous education to teach cultural and moral values and appropriate behaviours without directly and overtly moralizing and criticizing an individual. Many of these proverbs survived in the lyrics of Mende songs. Others are painted on buses and trucks across the country, for example (translated from Mende): 'No pain no gain'; 'Don't look where you fell, look where you tripped'; 'Nobody knows from which direction the wind will blow to bend the chicken's ear' (meaning: it's not always possible to predict the sources of one's good or bad fortune).

According to the findings by Yatta, the teaching of proverbs and folktales was not only done by parents or elders but generally by adult population of the society like grandparents, older siblings, uncles and aunts. Yatta (2007) confirms this amongst the Mende of Sierra Leone that adults would gather youngsters around a fire at night and tell them great stories and legends about the past that helped the youngsters to grasp the prevailing ethical standards of their community. From the Nso' native proverbs, Nso' children learn to practice socio-cultural values like respect for elders, humility, compassion, kindness, patience and guard against vices like greed, trouble making, bad company, selfishness, jealousy, dishonesty and anger. Olatunji (1985) buttresses this point when he says that proverbs serve as social characters to praise what the society considers to be virtues such as tolerance, responsibility, dedication, love, discipline, justice etc. In the same way, proverbs are used to condemn what the society considered injustice, intolerance, destruction, jealousy, envy, hatred and sexual immorality among others..

\section{Objective Two: How Indigenous Games Influence Emotion Regulation Adjustment.}

Quantitative results illustrate a great significance influence of indigenous games on the emotion regulation adjustment of early adolescents. In comparing problems solving ability (indicators of emotion regulation adjustment) as scored by practical experience of indigenous games. Findings reveal that indigenous games highly contribute to problem solving ability of children as most of them who had experienced of indigenous games portrait such ability against a significantly lower rate for those children who were not exposed to games. Problem solving ability of children exposed to indigenous games was not dependent on the socio-economic status of the parents. From the overall trend of the result, indigenous games proved to be the main source of high level of problem solving among the respondents. All indicators to measure the influence of indigenous games on the emotion regulation adjustment of early adolescents were highly significant.

Unlike proverbs, all the components of problem solving significantly explained emotion regulation adjustment of early adolescents and their EPs (explanatory power) were generally good, and the Integrated Value Mapping (IVM) had a very high explanatory power. This missing variability though small in a modelling context, indicates that there are other factors besides those considered in this study that enhance emotion regulation adjustment of early adolescents. Individual games impacted emotion regulation adjustment highly unlike proverbs whereby the aggregated effects of several of them was necessary to bring about a reasonable contribution to emotion regulation adjustment. In the other sense, a single component can influence diverse indicators of emotion regulation adjustment unlike proverbs. Comparing between male and female, it was realized that the EP was higher for females for the component, avoidance as a method of problem solving and was higher for males for the components compromise, dialogue and solicit for elderly intervention.

Discussions emerging from objective two are consistent with the works of Nyota and Mapara (2008) Nyota and Mapara (2008) carried out a study amongst the Shona people of Zimbabwe, it was discovered that Shona traditional children's games and songs lead to and provide a rich environment or social context that sustains the flowering of children's curiosity and exploration of their immediate world as they play. The children explore the social context of games and play songs through guided apprenticeship that is greatly rewarding and motivational. The virtues and values learnt are varied and practical. Some of them are good behaviour, Sharing (sensitive to other's needs), Humility, Group compliance, Respect for elders, Sense of appreciation, Self examination, Sense of collectivity, Selfcontrol, hard work, competition, handling success and failure and leadership which greatly promotes peer socialization through the exhibition of such cultural values. 
The researchers carried out the through the use of observation of Shona children as they played with their peers. The following findings were registered. It was observed that the young Shona child learns to play games through guided participation in a mentor-mentee relationship with more experienced peers. The researchers observed that many social skills can be learnt through Shona traditional children's games. For example, the children learn to share tools used for the games such as nhodo (a game similar to Jacks) and ndondo where necessary. They learn to manage conflict such as to respond to a playmate's accusation, for example, when a playmate says, "Wabira" (You have cheated), especially when the accuser has been beaten in a competitive game. They can also learn to keep friends and playmates. They can learn to manage and deal with those playmates who are not always understanding and self-sacrificing, for instance one who is always quick to denounce friendship, "Hausi shamwari yangu futi" (You are after all not my friend). These skills have consequences that teach the children about social interaction from youth to their adult years.

Nso native folktales that children knew were both human stories and those that personified animal characters. While these stories like Wanyeto and Nkuyam portrayed the character trait of each animal they equally sound some moral lessons for children. This falls in line with findings recorded by Yatta (2007) amongst the Mende people of Sierra Leone. According to Yatta, stories that personified animal characters were often told, and these stories, while explaining the peculiar trait of each animal, also transmitted the virtues valued by the society. For example, stories about kasiloi (the spider), always taught youngsters about the unwanted consequences of traits such as greed, egotism, disobedience, or cunning.

\section{Objective Three: To Determine if There is Gender Differences in Emotion Regulation Patterns}

Gender difference was considered in all three objectives of the study. From the overall statistical conclusion, there were no significant differences of emotion regulation adjustment among boys and girls through indigenous socialization strategies. The implication was that both boys and girls demonstrated overall equal abilities of regulating emotions through measured indigenous socialization strategies. The present investigation assumes both gender and children's games to be socially and historically constructed. As such, the form and meanings given to games differed from place to place and time to time. The study of games as a form of dynamic folklore, therefore, had the potential to confront the analytical categories of sex and dominant definitions of gender found within the Nso people. The following results, however, offer only broad historical trends in the game preferences of Nso boys and girls. The historical change in sex preferences for games was discussed initially, followed by an investigation of the change in types of games preferred by Nso children. Thus, the results and related discussion were discussed simultaneously in objectives one and two rather than as a distinct section

This objective constituted a comprehensive meta-analytic review of gender differences and moderators of differences in emotion expression of early adolescence. From the analysis, Significant but very small gender differences were found with girls showing more positive emotions and internalizing emotions (e.g., gossiping/slandering, sadness, anxiety, sympathy;) than boys, and boys showing more externalizing emotions (e.g., anger, fighting, and cheating ) and this difference was statistically. Notably, gender differences were moderated by age, interpersonal context, and task valence, underscoring the importance of contextual factors in gender differences. Gender differences in positive emotions were more pronounced with increasing age, with girls showing more positive emotions than boys. Boys showed more externalizing emotions than girls, and fewer externalizing emotions than girls in adolescence. Our findings of gender differences in emotion regulation adjustment in specific contexts have important implications for gender differences in early adolescent's ability to regulate emotions and culturally adapt to their context given considered indigenous socialization strategies utilized for the study. See appendix two.

Findings illustrate that, social competence in relation to experience or no experience of proverbs was not dependent of sex. .As for the group with experience of proverbs, the weight of those who portrait social competence was almost equally shared among the male and the female. As for those with no experience of proverbs, males portrait high social competence skills against a relatively lower rate for the female but this difference was not statistically significant. This simply means that, the elevated rate of social competence skills exhibited by both boys and girls exposed to indigenous proverbs could not be linked directly or associated to their knowledge and understanding of proverbs. This is so because early adolescents who were not exposed to proverbs still recorded a very high score on social 
competence skills. However, qualitative data from interviews indicate that other cultural values such as Sense of hospitality; Sense of the sacred and of religion; Sense of time; Sense of respect for authority and the elders; and Sense of language and proverbs contributed to the high acquisition of social competence skills by both respondents as discussed above. On the other hand, it was realized that indigenous games contribute highly to problem solving ability of early adolescent but more to the female than the male and this difference was statistically significant.

Findings uncovered by objective three were supported by a good number of research works, though indicators used in such studies to measure emotions regulation adjustment were not the same as those utilized by the present study, however, it explains gender difference in emotion regulation adjustment. For instance, (Holmbeck, \& Duckett, 2000) indicates that girls may be more closely connected with family during adolescence, especially in more intimate, interpersonal matters and girls' relationships are more likely than boys' to be characterized by emotional closeness . Personal relationships take a more central role in the lives of girls (Stiver, \& Surrey, 1991), and good quality relationships are more likely to influence girls' than boys' psychosocial outcomes (Berndt \& Keefe, 1995), including depression. Boys and girls also seek out friends and parents differently for support in solving interpersonal and other problems (Sullivan, Marshall, \& Schonert-Reichl, 2002). Although there is no gender difference in instrumental or problem- solving support seeking when under stress, girls are more likely than boys to seek emotional support (Greenberger \& McLaughlin, 1998). Thus girls' natural social networks are more likely to be characterized by close emotional relationships, which they are more likely to draw on in times of need and which affect them more strongly than boys.

\section{EDUCATIONAL IMPLICATIONS OF THE STUDY}

The current paradigm shift towards integrating and promoting indigenous education gravitate alternative approaches to school curricula in Cameroon particularly and Sub-Saharan Africa in general. There is now a growing consensus that some of the solutions to problems that currently plague African societies and communities must proceed from understanding the dynamics within the local context. Such dynamics include the role of indigenous strategies of socialization and practices in educational processes. This study supports the growing number of African educators calling for the re-conceptualization of schooling and education to bring about meaningful changes. This aspect of the dissertation focuses on integrating local/Indigenous cultural knowledge's emerging from the study in Cameroon's formal education. It deals with the importance of local teachings embedded in traditional Nso proverbs and indigenous games and how such cultural knowledge's can be used effectively to teach young learners.

Teachers' attitudes toward and beliefs about the value and potential contribution of indigenous knowledge to education define how they integrate this form of knowledge into the formal school curriculum. It was revealed through interviews conducted with teachers that, some of the challenges in the integration of indigenous knowledge in formal education arise from teachers' lack of faith that such a curriculum can actually contribute significantly in addressing the educational needs of the country. Teachers' inability to integrate indigenous knowledge in their practice as was revealed in this study, may also be resulting from limited knowledge on what aspects to be integrate. This view is supported by Somjee (1996) as he noted that although teachers are entrusted with the responsibility of fostering indigenous knowledge in the learning institutions of most sub Saharan countries, "there is no guidance on what aspects of culture are to be integrated into the curricula. The syllabus only tells teachers what they must do and should do, but not explain how to do it" see appendix.

There is also need as indicated by the study for teachers and teacher educators to adopt practices that embrace both western and indigenous knowledge in ways that defy dichotomous presentation, foster relevance, inculcate a sense of self-worth, and national pride among learners. As teachers and educators develop a more culturally inclusive curriculum practices, they must confront the emerging challenges from within themselves and the environment in which they are operating. It was as well realized that, for educators and teachers to effectively amalgamate indigenous knowledge such as proverbs and games, into the curriculum content, there is a need to transform individuals' perceptions of what constitutes legitimate and valuable school knowledge, learning, and teaching. Teachers and educators need to examine their practices and develop ways to authentically engage and legitimize indigenous knowledge forms into the formal education system. This view is supported by Mwenda (2003) who asserts, "It is time that African educators come to the realization that western diagnosis 
for educational development does not reflect Africa's realities". The purely western models of education are not capable of addressing the current socio-economic problems at the micro level, especially in the rural regions of Africa like Cameroon. Hence, there is a need to revitalize the presence of ethnic indigenous ways of knowing, pedagogy and practices in the educational system if Cameroonians are to redefine and re-shape their own socio-economic framework within their own terms of development at the micro level.

However, through this study, one can begin to appreciate the particulars of indigenous ways of knowing and their epistemologies. For example, in examining indigenous education and knowledge closely, we see that it involves understanding education as: a means to an end; social responsibility; spiral and moral values; participation in ceremonies, rituals; imitation; recitation; demonstration; sport; epic; poetry; reasoning; riddles; praise; songs; story-telling; proverbs, folktales; word games; puzzles; tongue-twisters; dance; music; plant biology; environmental education, and other education centred activity that can be acknowledged and examined. Some of the particulars of Nso culture and knowledge production that would otherwise educate the populous remain hidden, unless a pro-active community of scholars rescue it, and give it new meaning and significance. For example, this study added new light on both the traditional and educational relevance of enhancing cultural values through proverbs and indigenous games amongst children.

Instructively this information and similar data outlines a dynamic for a true African education that embody lessons of "...communal respect for the opinions of others, lessons of deference to elders, lessons about the importance of dialogue, lessons about conflict conciliation, the spirit of tolerance and forgiveness, and the spirit to face the future with an open mind" that can become a way to involve parents in the curriculum, and ascertain new lines of communication between schooling and indigenous knowledge. The study reveals that, schooling is an emotionally laden process for students, teachers and parents. Emotions are intimately involved in virtually every aspect of the teaching and learning process as they are, according to appraisal, based on an individual's cognitive interpretations and appraisals of specific situations. In addition, it is evidence that emotions serve as a powerful vehicle for enhancing or inhibiting learning as indicated by the study. These are some of the relationships between emotions and learning processes that justify a focus on classroom emotion regulation. This work is incomplete without its pedagogical implication particularly in the teaching learning process. This explains the imperativeness of this section and brings to light the link between emotion regulation, teaching and learning. Although more needs to be done to understand the affects of the use of specific emotion regulation strategies, particularly in relation to teacher pedagogical strategy used in the teaching / learning process, this research through interviews with teachers indicates that student emotion regulation strategy use may be an important indicator or tool of positive education outcomes. Indications to this point in time are that antecedent emotion regulation strategies such as proverbs and indigenous games have great benefits over response focused strategies. See appendix 2 thematic analysis.

According to the study, teachers can address the development of student antecedent emotion regulation in the classroom through a number of means. One way of doing this is to model such strategies that, in turn, may be used by students in the teaching learning process. This can assist teachers in addressing both their own and student emotions. A school focus on the importance of emotions and emotion development may frame pedagogy and curricula sufficiently such that specific structured programs are not necessary. Emotion development in the classroom can be fostered or frustrated by school structures that neglect indigenous epistemologies. No matter which way they are addressed, emotions in children's school experiences should not focus on what a child cannot do but more about framing the place of emotion in our schools. School and classroom environments that are structured around opportunities for expressivity, teacher autonomy support and a sense of belonging, as indicated by the study, are conducive to the healthy development of student emotion regulation strategies.

This research furthermore indicate that when students feel emotionally and academically supported by their teacher, they are more likely to use self-regulated learning strategies and student perception of teacher support has a direct effect on how motivated and interested students feel in the classroom. This is supported by Fried, 2010) as he asserts that, teacher support has a significant contribution to the emotion regulation of students Teacher support can be classified as either controlling or autonomy supportive. An autonomy supportive teaching style enables students to regulate aspects of their learning, including emotions. Evidence suggests that students are more successful and happier at 
school if they are encouraged to be autonomous; the degree of autonomy allowed depends on the student's stage, age, personality and attitudes.

It was recognized that many teachers have difficulty regulating the emotions of students in their classroom through proverbs and the overall emotional climate of the class. Training teachers to assist students with the regulation of their own emotions is therefore important. Teachers need a firm intellectual understanding of indigenous strategies of socialization and self-regulated learning in order to encourage students to develop these skills. It is important to recognize that student and teacher emotions and emotion regulation influence and are influenced by the emotional climate of the school as well as the principals, teachers, and parents with whom they interact. The role that emotions play in teachers' work tends to be downplayed or ignored in policy and standards frameworks. A greater understanding of the role of emotions in the teaching profession can help in the training of teachers to be well equipped to tackle the demands of the classroom and achieve the goal of educating students who can take greater control of their lives. Because emotions have a significant effect on learning and because schooling is an emotional process, there are times when students and teachers need to implement emotion regulation strategies in the classroom.

Although individuals differ in their emotion experiences and expression, it is possible that some strategies are more adaptive than others. This needs further investigation in future research. Means of enhancing emotion regulation in the classroom, through supportive, collaborative and expressive classroom environments as indicated in this work, although much is still to be learnt. Further research on emotions and emotion regulation should incorporate the classroom as it will help to reposition the importance of emotions and not only assist teacher's own emotional development but also their ability to facilitate healthy emotion development of their students. This study indicates that, Supportive peer relationships through indigenous games promote internalization of values, feelings of affective ties, relatedness or belongingness in students and enhance the well-being of all involved), thus support are an important dimension of socialization. In a school context, relationships with classmates are especially important part of their learning environment. Relationships with peers at school probably are important in promoting feelings of relatedness and belongingness to school. Support from classmates might be important in promoting a feeling of school-motivation, relatedness or belongingness.

\section{Conclusions}

The study indicates that, selected indigenous socialization strategies among Nso people (oral tradition) are key constituent of children's everyday life and the means through which they participate in the process of knowledge production and transmission. Through interpretation of oral tradition, children produce knowledge and are able to regulate their emotions effectively in the process of socialization. During interaction with each other as well as with adults in the performance of oral tradition, children transmit knowledge in adherence to their specific cultural values that promote not only emotion regulation adjustment, but contribute to their holistic development within the ecological setting. In this process, children make oral tradition part of their everyday life and understand their social world through it. It was also revealed that, rural children are embedded in intricate cultural practices, social orders and practices of generation-based division of labour and social responsibility.

Arguments in the dissertation imply that children living in the rural environment are capable of creatively adjusting and readjusting themselves to their relationships with contexts and actors in their social environments.' As social actors, the Nso children commonly live in three immediate social groups: with the family (at home), with teachers (in school) and with peers (during play or cultural activities). Through their interactions with these social groups the children use their oral tradition to create their own sense of attachment and socialize themselves with situations in the rural way of life. Such complexities depict rural early adolescents as different from urban children though not in a significant level as indicated by the study where less difference is observable between the social and cultural situations of children across home and school. In other words, children's double responsibility, which is to work and to attend school, characterizes rural children as different from urban childhood because in the latter, children's involvement in agricultural work is less or nonexistent. In other words, the fact that rural children combine play with work makes rural children unique. 
The article recognizes children as social actors in the events and processes of oral tradition ( indigenous games, proverbs, storytelling, tales etc) and this implies a different concept of 'culture' than that characterized by earlier studies of oral tradition among Oromo-speaking groups and other groups in Ethiopia as indicated in chapter two, which have chiefly been based on textual interpretations and, by neglecting the performative dimensions of proverbs and other forms of oral tradition, have ignored the fact that folktales and riddles are interpreted differently according to age, gender, social positions and thereby slipped into the danger of essentialist assumptions of 'culture'. The study demonstrates that conditions in the rural environment compel children to learn in their own ways through observation, imitation, role modelling and appropriation, which are the common ways in which children learn. Parents only guide children in this process. At home, children's learning takes places through observation and participation in everyday social practices and interactions, while in school it takes place through formal instruction by teachers. Oral tradition creates socially meaningful contexts for children's learning across these places. Through their work and oral tradition, children construe their dynamic social environments, correct the cultural and economic realities to fit into the realm of their everyday lives and cope with the values and challenges of the people they live with.

The main objective of informal learning as indicated by interviewed teachers for children in such places is to make themselves fit into the rural ways of life and survive the emotional, physical and social challenges that characterize the rural society. In this practice, children do not passively absorb the values and knowledge produced by adults but they negotiate with adults and appropriate the values and knowledge into their own social world that they require. In addition, children create and recreate their own child-centred values and knowledge through which they combine play with learning. Oral tradition facilitates these ways of children's learning. Thus, observation and appropriation in the process of oral tradition and the combined social practices enhance children's learning from three angles: cognitive, socio-emotional and cultural. The practices of creating and interpreting proverbs, folktales and riddles require children to exercise their mental processes such as thinking, associating, reciting and imagining. Again, through such oral processes, children make sense of the values and norms embodied in customary practices and further develop their cultural competence. Therefore, inclusion of oral tradition in the formal learning process enables children to connect their local knowledge to their lessons in the classroom and contextualize their learning process in which they enhance the authenticity of their learning activities. What can be noted from this study is that children's learning objectives and processes are culturally defined; the social and cultural contexts of children characterize what they prioritize to learn and how they prefer to learn. In the rural social and cultural context, the cultural complexity and agriculture based livelihoods demand that children must have a detailed knowledge of their immediate environment and skills needed for work and life. For example, in the tradition of household labour division that characterizes the rural family, children are expected to be skilful in exercising social roles.

Furthermore, this investigation indicates that Nso children are good at combining their oral play practice with their work, school, peer relationships and family interactions. Through such processes, children use oral tradition as a context of learning, play and cultural reproduction, as well as intragenerational and intergenerational interaction. In school, for instance, children are motivated to learn and can easily find meaning when they understand their lessons through their own life experience and everyday practices which they articulate by performance and interpretation of oral tradition. However, in the Nso context, it seems that school curriculum designers and policy makers as well as teachers are less aware of the power inherent in children's oral tradition and local knowledge to enhance the quality of children's formal and informal learning, which is reflected in school syllabuses. In other words, riddling and storytelling and the context of informal learning have not been well integrated in formal learning. Teachers' effort and skill to connect children's home context and cultural realities to learning in school and to enable children to relate school lessons to their everyday life fall far short of rural children's need for meaningful and friendly way of learning. Thus, the need to critically reflect on the curriculum and content of formal education by adapting a curriculum that is oriented to local knowledge is urgent. It is necessary to consider the power of oral tradition and children's local knowledge embedded in it to make learning activities meaningful for children and improve the quality of children's formal education. In this regard, three issues are worth considering. The first is further research on how to make the primary school curriculum compatible with children's local knowledge and everyday life. 


\section{REFERENCES}

Abdi, A., \& Cleghorn, A. (Eds.). (2005). Issues in African Education: Sociological Perspectives. New York: Palgrave Macmillan.

Abrahams, R. (1967). On Proverb Collecting and Proverb Collection. Proverbium, 8, 181-184.

Achenbach, T. M., \& Rescorla, L. A. (2000). Manual for the ASEBA preschool forms and profiles. Burlington: University of Vermont, Department of Psychiatry.

Allen, J. P. \& Hare, A. (2007, March). The Lasting Lessons of Early Adolescent Friendships: The Benefits of Autonomy and the Mixed Blessings of Early Intensity. Biennial Meetings of the Society for Research in Child Development, Boston, MA.

Anttonen, P.J. (2005). Tradition through Modernity: Postmodernism and the Nation-State in Folklore Scholarship. Helsinki Finish Literature Society.

Argenti, N. (2010). 'Things that Don't Come by the Road: Folktales, Fosterage, and Memories of Slavery in the Cameroon Grassfields', Comparative Studies in Society and History, 52(2), 224254.Arnold MB. (1960b) Emotion and personality: Vol. 2. Physiological aspects. New York: Columbia University Press;.

Ayers, T. S., Sandler, I. N., West, S. G., \& Roosa, M. W. (1990). Assessment of children's coping behaviours: Testing alternative models of coping. Poster presented at the annual meeting of the American Psychological Association, Boston

Baker, J. K., Fenning, R. M., \& Crnic, K. A. (2011). Emotion socialization by mothers and fathers: Coherence among behaviours and associations with parent attitudes and children's social competence. Social Development, 20, 412-430. doi: 10.1111/j.1467-9507.2010.00585.x

Barone, C., Aquirre-Deandries, A.I., Trickett, E.J. (1991). Means ends problem-solving skills, life stress, and social support as mediators of adjustment in the normative transition to high school. American Journal of Community Psychology, 19(2), 207-225.

Bayer, J. K., Sanson, A. V., \& Hemphill, S. A. (2006). Parent influences on early childhood internalizing difficulties. Journal of Applied Developmental Psychology, 27, 542-559.

Block, J.H. (1979). Another look at sex differences in the socialization behaviors of mothers and fathers. In J. Sherman \& F.L. Denmark (Eds.), Psychology of women: Future of research (pp.2987). New York: Psychological Dimensions.

Boateng, F. (1990). African Traditional Education: A Tool for Intergenerational Communication. In. M. K. Asante \& K. W. Asante (Eds.), African Culture: The Rhythms of Unity (pp.109-122). Trenton: African World Press.

Boyum, L. A., \& Parke, R. D. (1995). The role of family emotional expressiveness in the development of children's social competence. Journal of Marriage and the Family, 57, 593-608.

Bronfenbrenner, U. 1986. Ecology of the family as a context for Human Development: Research perspectives. Developmental Psychology. 22:723-742amre, B.K., and R.C. Pianta. 2001. Early teacher-child relationships and the trajectory of children's school outcomes through eighth grade. Child Development, 72(2):625-63

Brown, B.B. (2004). Adolescents' relationships with peers. In R.M. Lerner \& L. Steinberg (Eds.), The Handbook of Adolescent Psychology, 2nd Edition (pp. 363-394). London: John Wiley \& Sons.

Browne, M.W. \& Cudeck, R. (1993). Alternative ways of assessing model fit. In K.A. Bollen \& J.S. Long (Eds.), Testing structural equation models (pp. 445-455). Newbury Park, CA: Sage.

Bruner, J. (1991). 'The Narrative Construction of Reality', Critical Inquiry, 18(1), 1-21.

Campbell, S. B., \& Ewing, L. J. (1990). Follow-up of hard-to-manage preschoolers: Adjustment at age 9 and predictors of continuing symptoms. Journal of Child Psychology and Psychiatry, 31, 871-889.

Cassano, M., Perry-Parrish, C., \& Zeman, J. (2007). Influence of gender on parental socialization of children's sadness regulation. Social Development, 16, 210-231. doi: 10.1111/j.14679507.2007.00381.x

Cassidy, J., Parke, R. D., Butkovsky, L., \& Braungart, J. M. (1992). Family-peer connections: The roles of emotional expressiveness within the family and children's understanding of emotions. Child Development, 63, 603-618. 
Catanzaro, S.J., \& Laurent, J. (2004). Perceived family support, negative mood regulation expectancies, coping, and adolescent alcohol use: Evidence of mediation and moderation effects. Addictive Behaviors, 29(9), 1779-1797.

Chassin, L.A., Rogosch, R., \& Barrera, M., Jr. (1991). Substance use and symptomatology among Adolescent children of alcoholics. Journal of Abnormal Psychology, 100, 449-463.

Cheah, C., \& Chirkov, V. (2008). Parents' personal and cultural beliefs regarding young children: A crosscultural study of aboriginal and Euro-Canadian mothers. Journal of Cross-Cultural Psychology, 39, 402-423.

Clore GL, Ortony (2008) A. Appraisal theories: How cognition shapes affect into emotion. In: Lewis M, Haviland-Jones JM, Barrett LF, Handbook of emotions. 3rd ed. New York: Guilford Press; pp. 628-642.

Cohen, S., \& Wills, T.A. (1985). Stress, social support, and the buffering hypothesis. Psychological Bulletin, 98 (2), 310-357.

Cole, D.A., Michel, M.K, \& Teti, L.O. (1994). The development of emotion regulation and dysregulation: A clinical perspective. Monographs for the Society for Research in Child Development, 59, 73-100.

Colwell, M. J., \& Hart, S. (2006). Emotion framing: Does it relate to children's emotion knowledge and social behavior? Early Child Development and Care, 176, 591-603.

Combs-Ronto, L. A., Olson, S. L., Lunkenheimer, E. S., \& Sameroff, A. J. (2009). Interactions between maternal parenting and children's early disruptive behavior: Bidirectional associations across the transition from preschool to school entry. Journal of Abnormal Child Psychology, 37, 1151-1163.

Connell, A.M., \& Dishion, T.J. (2008). Reducing depression among at-risk early adolescents: Threeyear effects of a family-centered intervention embedded within schools. Journal of Family Psychology, 22, 574-585.

Conway, A. (2005). Girls, aggression, and emotion regulation. American Journal of Bloomington, IN: Indiana University Press.

Corsaro, W. A. and Molinari, L. (2000). 'Entering and Observing Children's World: A Reflection on a Longitudinal Ethnography of Early Education in Italy.' In P. Christensen and A. James (eds), Research with Children: Perspectives and

Crockett, L.J., Raffaelli, M., \& Shen, Y.L. (2006). Linking self-regulation and risk proneness to risky sexual behavior: pathways through peer pressure and early substance use. Journal of Research on Adolescence, 16, 503-525.

Cummings, E. M., Iannotti, R. J., \& Zahn-Waxler, C. (1989). Aggression between peers in early childhood: Individual continuity and developmental change. Child Development, 60, 887-895.

Dasen, P. R. (2011). Culture, cognition and learning. In A. Bame Nsamenang \& T. S. Tchombe (Eds.). Handbook of African educational theories and practices: A generative teacher education curriculum contents (pp. 187-202). Bamenda, Cameroon: Human Development Resource Centre.

Davenport, B. R., Hegland, S., \& Melby, J. N. (2007). Parent behaviours in free-play and problemsolving interactions in relation to problem behaviours in preschool boys. Early Child Development and Care, 178, 1-19. doi:

Delaney, K.R. (2006). Following the affect: learning to observe emotional regulation. Journal of Child and Adolescent Psychiatric Nursing, 19, 175-181.

Demuth, C. (2008). Talking to infants: How culture is instantiated in early mother-infant interactions. The case of Cameroonian farming Nso and North German middle-class families. Unpublished doctoral dissertation, University of Osnabruck, Faculty of Human Sciences, Department of Culture \& Psychology.

Denham (Eds.), The role of gender in the socialization of emotion: Key concepts and critical issues. New Directions for Child and Adolescent Development, 128, (pp. 29-49). San Francisco: JosseyBass. doi: 10.1002/cd.267

Duncan, T.E., Duncan, S.C., \& Hops, H. (1994). The effects of family cohesiveness and peer encouragement on the development of adolescent alcohol use: A cohort-sequential approach to the analysis of longitudinal data. Journal of Studies on Alcohol, 55(5), 588-599. 
Dunn, J., Brown, J., Slomkowski, C., Tesla, C., \& Youngblade, L. (1991). Young children's understanding of other people's feelings and beliefs: Individual differences and their antecedents. Child Development, 62, 1352-1366.

Fabes, R.A., Poulin, R.E, \& Eisenberg, N., Madden-Derdich, D.A. (2002). The Coping with Children's Negative Emotions Scale (CCNES): Psychometric properties and relations with children's emotional competence. Marriage \& Family Review, 34(3-4), 285-310.

Feindler, E.L., \& Starr, K.E. (2003). From Steaming Mad to Staying Cool: A Constructive Approach to Anger Control. Reclaiming Children and Youth, 12, 158-160.

Fernandez, I., Paez, D., Carrera, P., Sanchez, F., \& Candia, J. L. (2000). Differences between cultures in emotional verbal and non-verbal reaction. Psicothema, 12, 83-92.

Finkenauer, C., Engels, R.C.M.E., \& Baumeister, R.F. (2005). Parenting behavior and adolescent behavioural and emotional problems: The role of self-control. International Journal of Behavioral Development, 29, 58-69.

Flores, J. P., et al (2004, May). Telling selves in time: Aboriginal and nonaboriginal accounts of identity. Paper presented at the University of Saskatchewan, Culture and Human Development Workshop Saskatoon, Saskatchewan.

Flores, J. P., Teuchner, U. C., \& Chandler, M. J. (2004, May). Telling selves in time: Aboriginal and nonaboriginal accounts of identity. Paper presented at the University of Saskatchewan, Culture and Human Development Workshop Saskatoon, Saskatchewan.

Goodwin, R.D. (2006). Association between coping with anger and feelings of depression among youths. American Journal of Public Health, 96, 664-669.

Gottman, J. M., Katz, L. F., \& Hooven, C. (1996). Parental meta-emotion philosophy and the emotional life of families: Theoretical models and preliminary data. Journal of Family Psychology, 10, 243-268. doi: 10.1037/0893-3200.10.3.243

Gresham, F., \& Elliott, S. (1990). Social Skills Rating System: Parent Form, Elementary Level. Circle Pines, MN: American Guidance Service.

Griffen, K.W., Botvin, G.J., Scheier, L.M., Diaz, T., \& Miller, N.L. (2000). Parenting practices as predictors of substance use, delinquency, and aggression among urban minority youth: Moderating effects of family structure and gender. Psychology of Addictive Behaviors, 14(2), 174-184.

Grolnick, W. S., Bridges, L. J., \& Connell, J. P. (1996). Emotion regulation in two-yearolds: Strategies and emotional expression in four contexts. Child Development, 67, 928-941.

Gross JJ, Thompson RA. (2007) Emotion regulation: Conceptual foundations. In: Gross JJ, editor. Handbook of emotion regulation. New York, NY: Guilford press pp. 3-24.

Gross JJ. (1998) The emerging field of emotion regulation: An integrative review. Review of General Psychology. 2:271-299

Grossman, P., \& Taylor, E.W. (2007). Toward understanding respiratory sinus arrhythmia: Relations to cardiac vagal tone, evolution and biobehavioral functions. Biological Psychology, 74, 263285.

Jaleta, T. (2009). The Contextual Study of the Social Functions of Guji Oromo Proverbs: The Savor and Rhetoric of Verbal Arts in Everyday Communications of African Peoples. Deutschland: VDM Verlag.

Jirata, T.J. (2008). 'The Gondoro: Folklore as a Mode of Cultural Contact and Means of 103 coexistence in a Pluralist Society.' Annual Conference on Conflict Prevention, Resolution Management and Transformation in Ethiopia: Multidimensional Approach, 20- 23 February, Addis Ababa University.

Kağitcibaşi, C. (1996). Family and human development across countries: A view from the other side. Mahwah, NJ: Lawrence Erlbaum.

Kaiser, A. P., Hancock, T. B., Cai, X., Foster, E. M., \& Hester, P. P. (2000). Parentreported behavioral and language delays in boys and girls enrolled in Head Start classrooms. Behavioral Disorders, 26, 26-41.

Kandel, D.B., \& Davies, M. (1982). Epidemiology of depressed mood in adolescents. Archives of General Psychiatry, 39, 1205-1212. 
Kartner, J., Keller, H., Lamm, B., Abels, M., Yovsi, R. D., \& Chaudhary, N. (2007). Manifestations of autonomy and relatedness in mothers' accounts of their ethnotheories regarding childcare across five cultural communities. Journal of Cross-Cultural Psychology, 38, 613-628.

Kartner, J., Keller, H., Lamm, B., Abels, M., Yovsi, R. D., Chaudhary, N., et al. (2008). Similarities and differences in contingency experiences across sociocultural contexts. Infant Behavior \& Development, 31, 488-500.

Keller, H. (2003). Socialization for competence: Cultural models of infancy. Human Development, $46,288-311$.

Kjørholt, A.T. (2004). 'Childhood as a Social and Symbolic Space: Discourses on Children as Social Participants in Society.' PhD thesis, NTNU.

Klimes-Dougan, B., \& Zeman, J. (2007). Introduction to the special issue of social development: Emotion socialization in childhood and adolescence. Social Development, 16, 203-209.

Knauth, D.G., Skowron, E.A., \& Escobar, M. (2006). Effect of differentiation of self on adolescent risk behavior. Nursing Research, 55, 336-345.

Kobak, R.R., Sudler, N., \& Gamble, W. (1991). Attachment and depressive symptoms during adolescence: A developmental pathways analysis. Development and Psychopathology, 3, 461474.

Kokkonen, M. \& Kinnunen, M. (2006) Emotion regulation and well-being. In L. Pulkkinen, J. Kaprio, \& R.J. Rose (Eds.) Socioemotional Development \& health from Adolescence to Adulthood, (pp. 197-208) New York: Cambridge.

Koole, S. (2009). The psychology of emotion regulation: An integrative view. Cognition and Emotion, 23, 4-41.

Kopp, C. B., \& Neufeld, S. J. (2003). Emotional development during infancy. In R. J. Davidson, K. R. Scherer, \& H. H. Goldsmith (Eds.), Handbook of affective sciences (pp. 347-374). New York: Oxford University Press.

Kovacs, M., \& Devlin, B. (1998). Internalizing disorders in childhood. Journal of Child Psychology and Psychiatry, 1, 47-63.

Kring, A. M. \& Bachorowski, J. A. (1999). Emotion and psychopathology. Cognition and Emotion. 13, 575-599.

Krohne, H. W., Pieper, M., Knoll, N., \& Breimer, N. (2002). The cognitive regulation of emotions: The role of success versus failure experience and coping dispositions. Cognition and Emotion, $16,217-243$.

Lamb, M., \& Malkin, C. (1986). The development of social expectations in distress-relief sequences: A longitudinal study. International Journal of Behaviour Development, 9, 235- 249. 174

Lamborn, S.D., Mounts, N.S., Steinberg, L., Dornbusch, S.M. (1991). Patterns of competence and adjustment among adolescents from authoritative, authoritarian, indulgent, and neglectful families. Child Development, 62(5), 1049-1065.

Landry, S. H., Smith, K. E., Miller-Loncar, C. L., \& Swank, P. R. (1998). The relation of change in maternal interactive styles to the developing social competence of full-term and preterm children. Child Development, 69, 105-123.

Langrock, A.M., Compas, B.E., Keller, G., Merchant, M.J., \& Copeland, M.E. (2002). Coping with stress of parental depression: Parents' reports of children's coping, emotional, and behavioral problems. Journal of Clinical Child and Adolescent Psychology, 31(3), 212-224.

Maccoby, E.E. and J,A. Martin. 1983. Socialization in the context of die family: Parent-child interaction. In P. H. Mussen (Series Ed.) \& E. M. Hetherington (Vol. Ed.) Handbook of child psychology: Vol. 4. Socialization, personality, and social development (4th ed., pp. 1-101). New York: Wiley,

Markus, H. R., \& Kitayama, S. (1991). Culture and the self: Implications for cognition, emotion, and motivation. Psychological Review, 98, 224- 253.

Mead, M. (1928). Coming of age in Samoa. New York: Morrow. Super, C. M., \& Harkness, S. (1986). The developmental niche: A conceptualization at the interface of child and culture. International Journal of Behavioural Development, 9,545-569. 
Dynamics of Indigenous Socialization Strategies and Emotion Regulation Adjustment among Nso Early Adolescents, Norht West Region of Cameroon

Mechling, J. (1986). 'Children's Folklore.' In E. Oring (ed.), Folk Groups and Folklore Genres: An Introduction, (pp. 91-120). Logan, UT: Utah State University Press.

Meire, J. (2007). 'Qualitative Research on Children's Play: A Review of Recent Literature.' In T. Jambor and J.V. Gils (eds), Several Perspectives on Children's Play: Scientific Reflections for Practitioners, (pp. 29-78). London: Garant Publishers. 105

Mello, R. (2001). 'The Power of Storytelling: How Oral Narrative Influences Children's Relationships in Classrooms', International Journal of Education and the Arts, 2(1). Accessed from: http://www.ijea.org/v2n1/

Miller, P.A., Kliewer, W., Hepworth, J.T., \& Sandler, I.N. (1994). Maternal socialization of children's Post divorce coping: Development of a measurement model. Journal of Applied Developmental Psychology, 15 (3), 457-487.

Mirabile, S. P., Scaramella, L. V., Sohr-Preston, S. L. , \& Robison, S. D. (2009) Mothers' socialization of emotion regulation: The moderating role of children's negative emotional reactivity. Child \& Youth Care Forum, 38, 19-37.

Mushengyezi, A. (2008). 'Children's Play Songs of the Baganda: Audience Dynamics, Form and Social Value.' In D. Dipio, L. Johannessen and S. Sillars (eds), Performing Community: Essays on Ugandan Oral Culture, (pp. 235-248). Oslo: Novus Press.

Nsamenang, A.B. (2002). Adolescence in Sub-Saharan Africa: An Image Constructed at the Interface Africa's Triple Inheritance. In B. B. Brown, R. Larson, \& T.S. Saraswathi (Eds.), The World's Youth: Adolescence in Eight Regions of the Globe. London: Cambridge University Press.

Nsamenang, A.B. \& M.E. Lamb (1994). Socialization of Nso children in the Bamenda Grassfields of northwest Cameroon. In P.M. Greenmailed \& RR Cocking (Eds.), Cross-Cultural roots of minority child development. Hillsdale, NJ: Erlbaum.

Nsamenang, A.B. \& M.E. Lamb (1995). The force of beliefs: How the parental values of the Nso of Northwest Cameroon shape children's progress towards adult models. Journal of Applied Developmental Psychology, 16 (4), 613-627.

Nsamenang, A.B. (1992). Perceptions of parenting among the Nso of Cameroon. In B.S. Hewlett (Ed.), Father-child relations: Anthropological and biosocial perspectives. New York: Aldine de Gruyter.

Nyota, S., \& Mapara,J., (2008) Shona Traditional Children's Games and Play: Songs as Indigenous ways of knowing, Journal of Pan African Studies, Vol.2, no. 4, June,pp189-202. Roux, J. C.,

O'Neal, C.R, \& Magai, C. (2005). Do parents respond in different ways when children feel different emotions? The emotional context of parenting. Development and Psychopathology, 17(2),467487.

Oakland, T. (2009). How universal are test development and use? In E. Grigorenko (Ed.). Assessment of abilities and competencies in an era of globalization (pp. 1-40). New York: Springer.

Ohannessian, C.M., Hesselbrock, V.M., \& Kramer, J. (2005). The Relationship between parental psychopathology and adolescent psychopathology: An examination of gender patterns. Journal of Emotional and Behavioral Disorders,

Parker, J. G., \& Gottman, J. M. (1989). Social and emotional development in a relational context: Friendship interaction from early childhood to adolescence. In T. J. Berndt, \& G.W. Ladd (Eds.), Peer relationships in child development (pp. 95 131). New York: Wiley.

Pasiak, C., Norman, J., \& Menna, R. (2011, June). The effect of mother-child interactional synchrony: Implications for preschool aggression and social competence. Poster session presented at the Canadian Psychological Association's 72nd Annual Convention, Toronto, Ontario.

Patterson, G. R., \& Stouthamer-Loeber, M. (1984). The correlation of family management practices and delinquency. Child Development, 55, 1299-1307.

Patterson, G. R., Dishion, R. J.,\& Bank, L. (1984). Family interaction: A process model of deviancy training. Aggressive Behavior, 10, 253-267. 
Pendry, P., \& Adam, E.K. (2007). Associations between parents' marital functioning, maternal parenting quality, maternal emotion and child cortisol levels. International Journal of Behavioral Development, 31, 218-231.

Petersen, A.C., Compas, B.E., Brooks-Gunn, J., Stemmler, M., Ey, S., \& Grant, K.E. (1993). Depression in adolescence. American Psychologist, 48, 155-168.

Robson, E., Panelli, R. and Punch, S. (2007). 'Conclusions and Future Directions for Studying Young Rural Lives.' In R. Panelli, S. Punch and E. Robson (eds), Global Perspectives on Rural Childhood and Youth, (pp.219-228). New York:

Rogoff B. et al. 1993. Guided Participation in Cultural Activity by Toddlers and Caregivers. Monographs of the Society for Research in Child Development, 58. Series Number 236.

Roseman, I. J., Dhawan, N., Rettek, S. I., \& Naidu, R. K. (1995). Cultural differences and crosscultural similarities in appraisals and emotional responses. Journal of Cross-Cultural Psychology, 26, 23-48.

Saarni, C. (1989). Children's understanding of strategic control of emotional expression in social transactions. In C. Saarni \& P. L. Harris (Eds.) Children's understanding of emotion (pp. 181208). New York: Cambridge University Press.

Stoker, S. C. (2002). Emotion regulation in high-risk young children. Dissertation Abstracts International: Section B, 63, 2077.

Straub, J. (2006). Understanding cultural differences. Relational hermeneutics and comparative analysis in cultural psychology. In J. Straub, D. Weidemann, C. Kolbl, \& B. Zielke (Eds.), Pursuit of meaning. Theoretical and methodological advances in cultural and cross-cultural psychology (pp. 163-215). Bielefeld: transcript Verlag.

Super, C. M., \& Harkness, S. (1996). The cultural structuring of child development. In J. W. Berry, P. R. Dasen, \& T. S. Saraswathi (Eds.), Handbook of cross-cultural psychology, Vol. 2: Basic processes and human development (2nd ed., pp. 1-39). Boston: Allyn \& Bacon.

Taylor, S. E., Sherman, D. K., Kim, H. S., Jarcho, J., \& Takagi, K. (2004). Culture and social support: Who seeks it and why? Journal of Personality and Social Psychology, 87, 354-362.

Thompson, R. A. (1990). Emotion and self-regulation. In R. A. Thompson (Ed.), Socioemotional development. Nebraska Symposium on Motivation (Vol. 36, pp. 383-483). Lincoln: University of Nebraska Press,

Vygotsky, L. S. (1978). Mind in society: The development of higher psychological processes. Cambridge, MA: Harvard University Press.

Walden, T.A., \& Smith, M.C. (1997). Emotion regulation. Motivation and Emotion, 21, 7-25.

Warren, H. K., \& Stifter, C. A. (2008). Maternal emotion-related socialization and preschoolers' developing emotion self-awareness. Social Development, 17, 239-258. doi: 10.1111/ j.14679507.2007.00423.x

Waters, S. F., Meyer, S. C., Jochem, R. A., Virmani, E. A., Raikes A., \& Thompson, R. A. (2009). Maternal perceptions of children's emotions: Individual differences and their correlates. Poster presented at the Biennial Meeting of the Society for Research in Child Development, Denver, $\mathrm{CO}$.

Webster-Stratton, C., \& Hammond, M. (1998). Conduct problems and level of social competence in Head Start children: Prevalence, pervasiveness, and associated risk factors. Clinical Child and Family Psychology Review, 1, 101-124.

Whitney, D., \& Trosten-Bloom, A. (2010). The power of appreciative inquiry (2nd ed.). San Francisco, CA: Berrett-Koehler.

Winsler, A.,., \& Chabay, L. A. (2000). Verbal self-regulation over time in preschool children at risk for attention and behaviour problems. Journal of Child Psychology and Psychiatry, 41, 875-886.

Wyness, M. (2009). 'Adults' Involvement in Children's Participation: Juggling Children's Places and Spaces', Children and Society, 23 (6), 395-406.

Yap, M.B.H., Allen, N.B., \& Sheeber, L. (2007). Using an emotion regulation framework to understand the role of temperament and family processes in risk for adolescent depressive disorders. Clinical Child and Family Psychology, 10, 180-196. 120 
Dynamics of Indigenous Socialization Strategies and Emotion Regulation Adjustment among Nso Early Adolescents, Norht West Region of Cameroon

Yovsi, R. D. (2003). An investigation of breastfeeding and mother-infant interactions in the face of cultural taboos and belief systems. The case of Nso and Fulani mothers and their infants of 3-5 months of age in Mbvem, Sub-division of the North-west province of Cameroon. Munster: Lit.

Yovsi, R., Kartner, J., Keller, H., \& Lohaus, A. (2009). Maternal interactional quality in two cultural environments: German middle-class and Cameroonian rural mothers. Journal of Cross-Cultural Psychology, 40(4), 701-707.

Zahn-Waxler, C. (2010). Socialization of emotion: Who influences whom and how? In A. Kennedy Root \& S. Denham (Eds.), The role of gender in the socialization of emotion: Key concepts and critical issues. New Directions for Child and Adolescent Development, 128, (pp. 101-109). San Francisco: Jossey-Bass. doi: 10.1002/cd.271

Zeman, J., Klimes-Dougan, B., Cassano, M., \& Adrian, M. (2007). Measurement issues in emotion research with children and adolescents. Clinical Psychology: Science and Practice, 14, 377-401.

Zimmerman, P., Maier, M.A., Winter, M., \& Grossmann, K.E. (2001). Attachment and adolescents' emotion regulation during a joint problem-solving task with a friend. International Journal of Behavioral Development, 25, 331-343.

\section{AUTHORS' BIOGRAPHY}

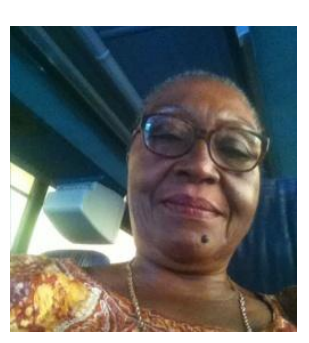

Emeritus Professor, Therese Mungah-Shalo TCHOMBE, is the UNESCO Chair for Special Education/ Inclusive Education and Honorary Dean at the faculty of Education, University of Buea Cameroon. She is an Emeritus Professor of Applied Cognitive Developmental Psychology. Her Other Areas of interest include Gender and Education, Girl's Access to Education, Teacher Education, Teacher's Interactive Behaviour, Education and ICT. Professor, T. S TCHOMBE had her Ph.D. at the London University Institute of Education/ University of Bristol, UK, 1984, M.Ed. University of Bristol, UK 1981, and a Bachelor degree at Digby Stuart College of Education an Affiliated College of London University Institute of Education and University of Bristol 1979. She started teaching as a University lecturer in 1986 and as full time lecturer in October $1^{\text {st }} 1990$ where she was moved from Assistant to Senior Lecturer, Associate Professor and full Professor since 2004. She has held educational administrative positions such as Head of Department of Sciences Education at the Ecole Normale Superieure ENS in the University of Yaoundé 1 from 1999 to 2005, Dean of the Faculty of Education at the University of Buea from 2006 to January 2009. Emeritus Professor, Therese Mungah-Shalo TCHOMBE She has supervised more than $15 \mathrm{PhD}$ Theses; 6 DEA (French Degree, A little bit above the Master degree), 33 Masters Theses all successfully defended with majority earning A grades and the others B+ and more 90 Post graduate Diplomas (Two years after First degree) 75\% earning A grades and the rest $\mathrm{B}+$ and $\mathrm{B}$ grades. She has published more than 58 articles, 27 book chapters, presented more than 57 scientific papers around the world_she has end several Honours and Awards and author of 11 Books. Professor, T. S TCHOMBE is a Research Consultant and chief editor to several journals.

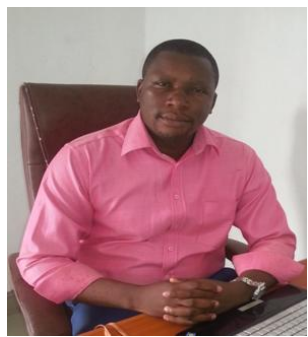

Dr. Tani Emmanuel Lukong, is Lecturer of Inclusive Education and Educational Psychology. Tani Emmanuel has a $\mathrm{PhD}$ in Psychology of Education with Triple Concentration in, Inclusive Education, Cognitive and Developmental Psychology and Applied cultural Psychology, a Master Degree in Psychology of Education and Bachelor's degree in Special Needs Education.

Dr. Tani Emmanuel is a University lecturer and the founder of "Foundation of Scientific Research, Community Based Rehabilitation and Advocacy on Inclusive Education" (Forcaie-Cameroon). A Research Organization aimed at building mutual-help, Equal Participation, Accessible Society with Love and care through the Utilization of Available Resources in Building up an Inclusive Rehabilitation Platform which promotes the Equal Participation of people with disabilities and enhances Community Development. Dr. Tani is a Research Consultant and Inclusive Education Specialist. 